\title{
Structural design of a 4-meter off- axis space telescope for the Habitable-zone Exoplanet Direct Imaging Mission
}

William R. Arnold, Sr.

Al Solutions, Huntsville, Al.

H. Philip Stahl

NASA MSFC, Huntsville, AI. 
This design study was conducted to support the HABEX project. There are a number of companion papers at this conference which go into detail on what all the HABEX goals are. The objective of this paper is to establish a baseline primary mirror design which satisfies the following structural related requirements.

The designs in this study have a high TRL (Technology Readiness Level), realistic manufacturing limits and performance in line with the HABEX mission.

A secondary goal of the study was to evaluate a number competing criteria for the selection. Questions such as differences in the on axis versus off axis static and dynamic response to disturbances.

This study concentrates on the structural behavior, companion papers cover thermal and long term stability aspects of the problem. 


\section{(a) SOME OF THE QUESTIONS WE WHAT TO ANSWER}

- Can we use on-axis models to understand the behavior of offaxis designs? [to take advantage of a lot of existing experience and "rules of thumb"]

- Is the static response to acceleration a good indicator of how the mirror (and suspension) will respond to harmonic disturbances? [for on-axis versus off-axis systems]

-What is the best operational suspension system for different coronagraphs? [attachment diameter \& number of locations]

- Other issues: how to best present the huge volume of results of the study? [plots, tables, etc.] 


\section{GROUND RULES OF THIS STUDY}

- MATERIALS: ULE ${ }^{\odot}$ and ZERODUR ${ }^{\odot}$

- ULE MANUFACTURING LIMITATIONS

- FRIT BOND ASSEMBLY

- CORE DEPTH LIMITED BY WATER JET (CURRENT PRACTICE)

- FRONT AND BACK FACE STYLE (ISOGRID OR UNIFORM THICKNESS)

- ZERODUR MANUFACTURING LIMITATIONS

- DEPTH CONTROLLED BY FURNANCE CAPACITY (TOTAL VOLUME)

- DEMONSTRATED POCKET MILLING METHODS

- STRAIGHT WALL, MODERATE UNDERCUT \& EXTREME UNDERCUT (SOFIA)

- MIRROR SHAPE

- MENISCUS, FLAT BACK, CONCAVE BACK, CONVEX BACK AND SCALLOPED

- DIMENSIONS

- TO BEST SHOW THE EFFECTS OF GEOMETRY, FOR THIS STUDY THE WALL AND FACE THICKNESS OF EACH GROUP (ULE \& ZERODUR) REMAIN THE SAME. These values are reasonable current capabilities, not necessarily the ultimate lightweighting possibilities.

- ONLY CELL SIZE, AND SUSPENSION (3 POINT, 6 POINT AND 100\%,75\%,65\% DIAMETER) ARE VARIED.

- ANGLE AND STIFFNESS OF HEXAPOD AS CLOSE TO EQUAL AS PRACTICAL FOR ALL CASES. 


\section{(d) ALL DESIGNS BASED UPON ESTABLISHED CONCEPTS}

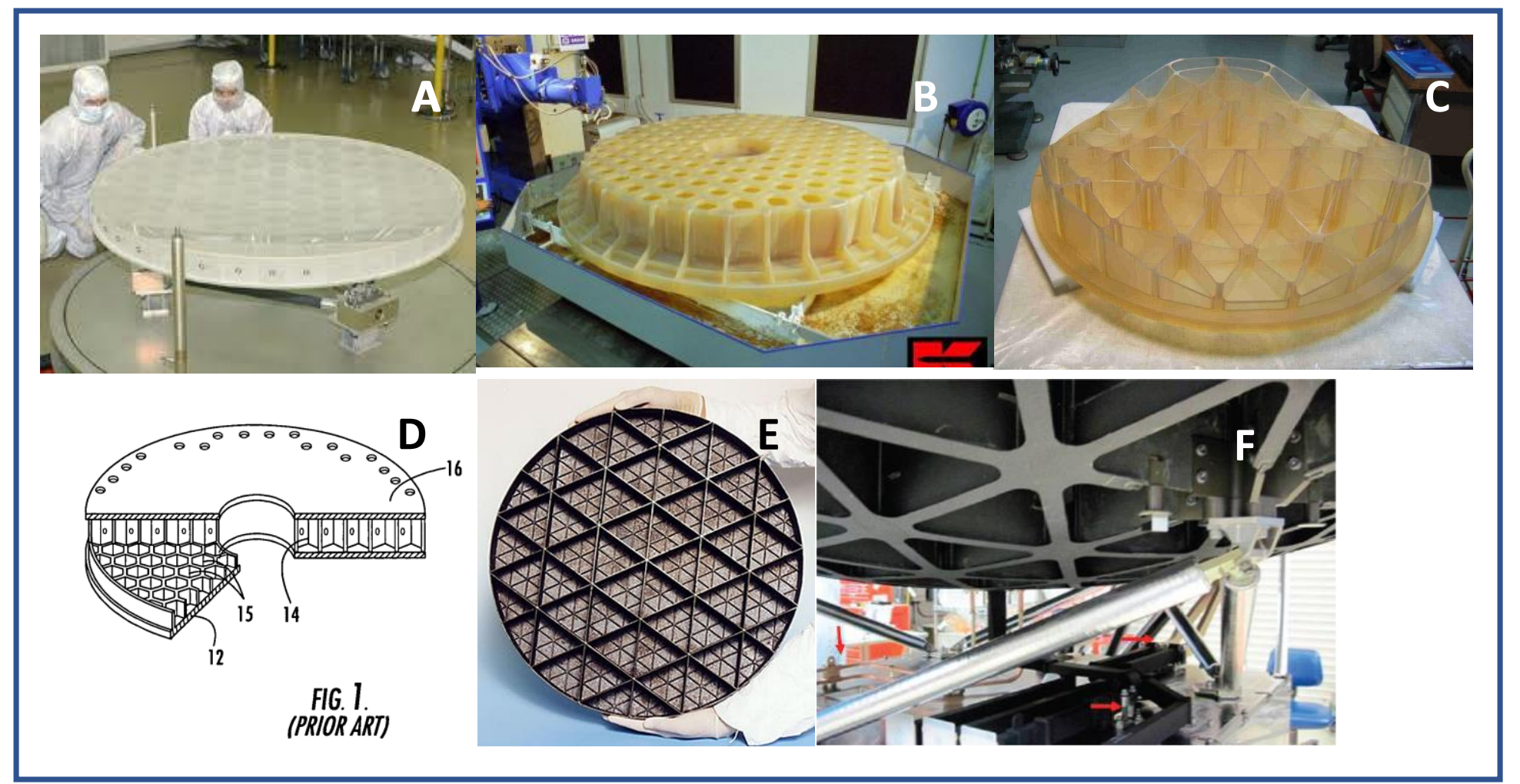

A KELPER

B SOFIA

C SUNRISE

D ISOGRID PATENT

E MULTI-LEVEL ISOGRID

F EDGE BEAM

Some of these concepts shown in this study may be patented or require proprietary manufacturing processes, which might restrict which manufacturers can build them, but all the options are variations which have been disclosed in the open literature. 


\section{ULE FRIT BONDED OPTIONS}

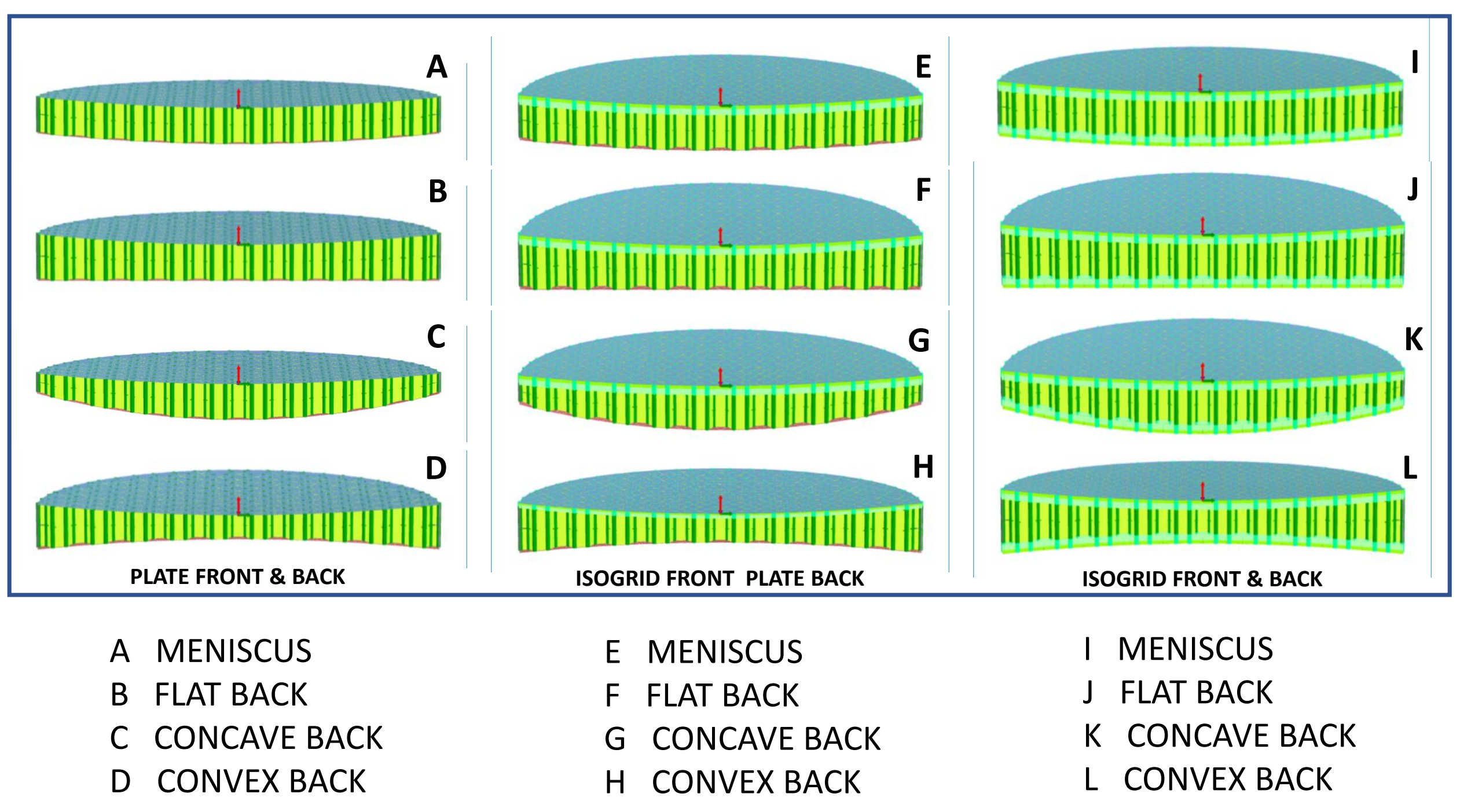




\section{ZERODUR DESIGN OPTIONS}

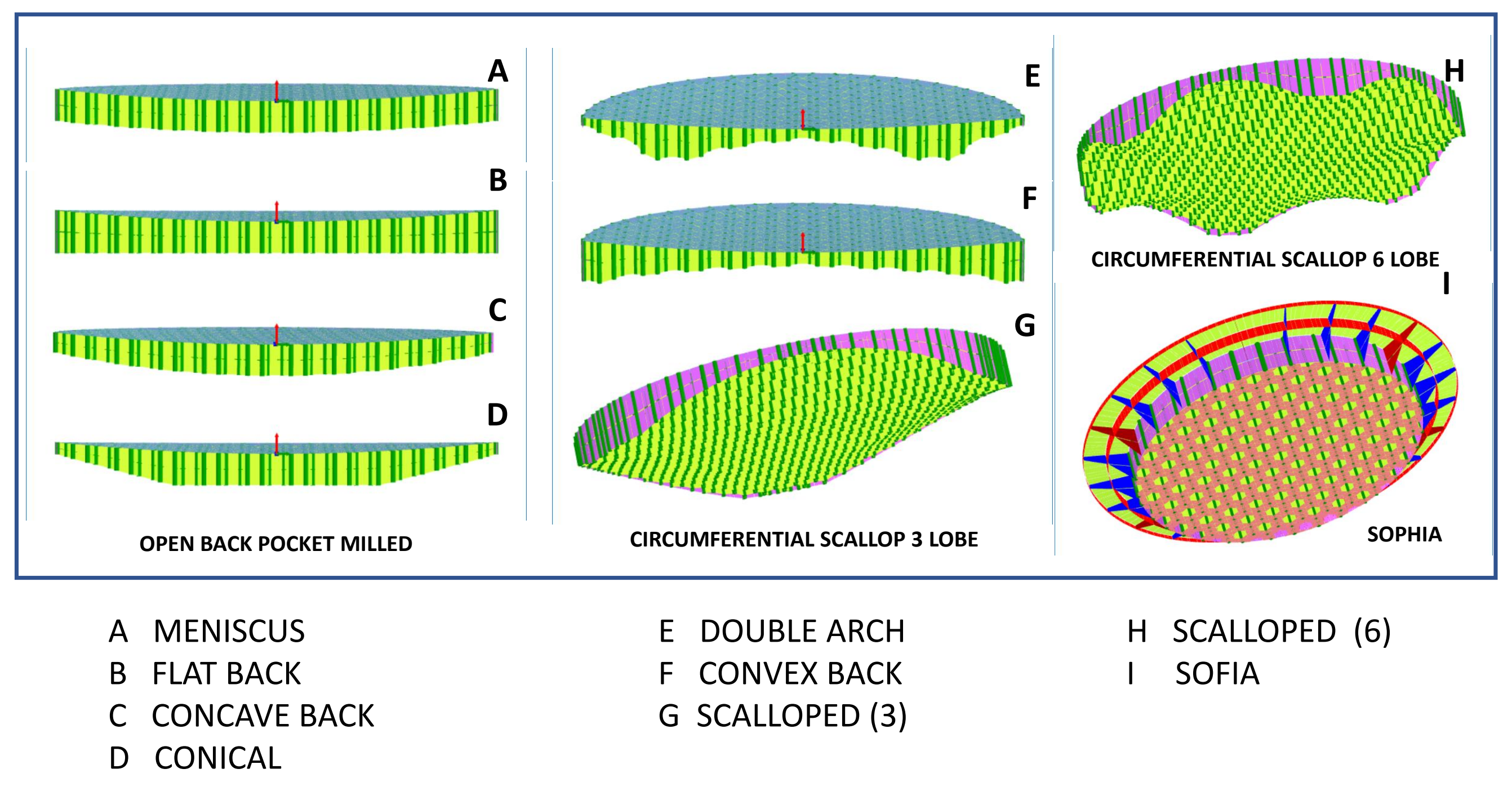




\section{THREE LEVELS OF UNDERCUT MILLING}
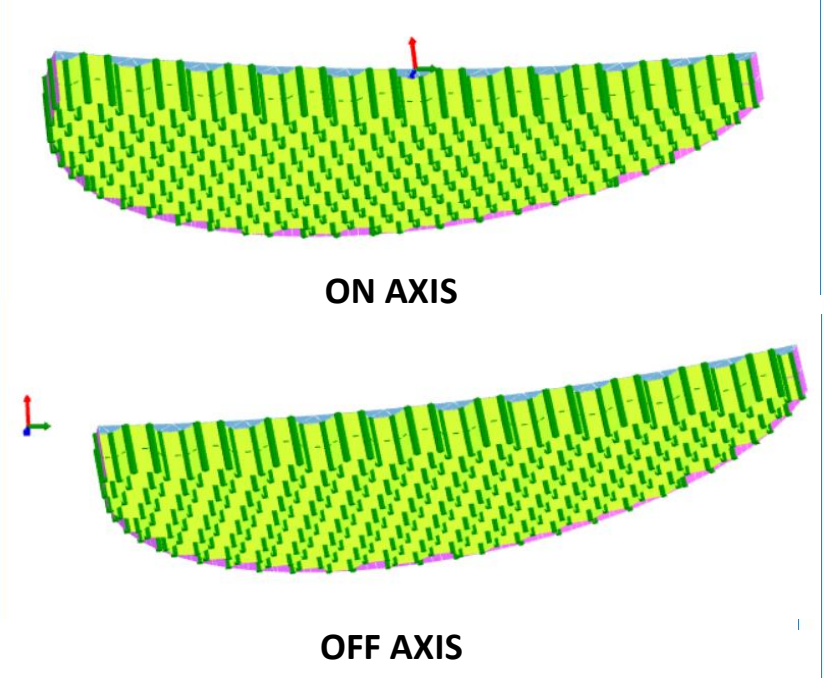

STRAIGHT MILLED
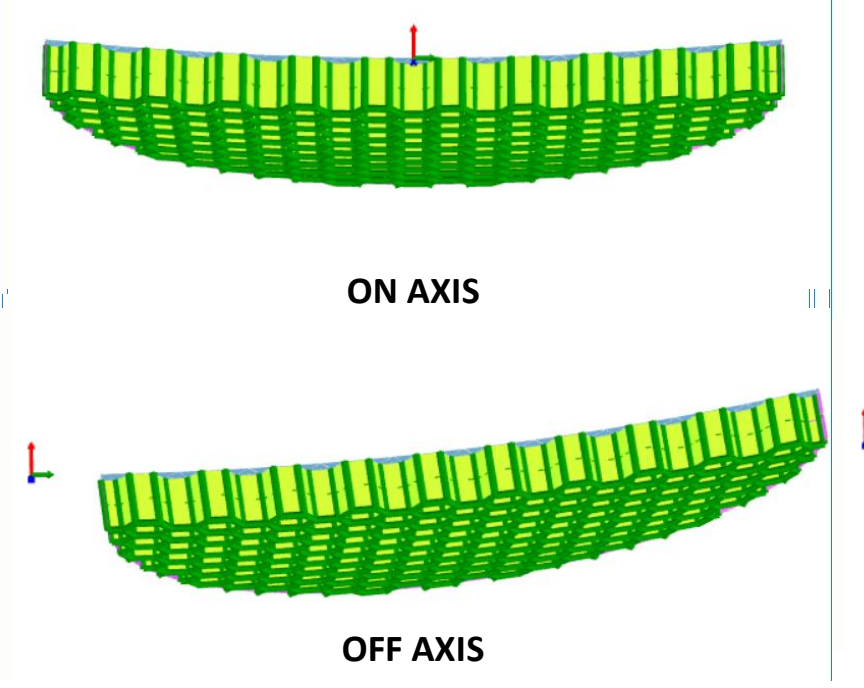

MODERATE UNDERCUT MILLED
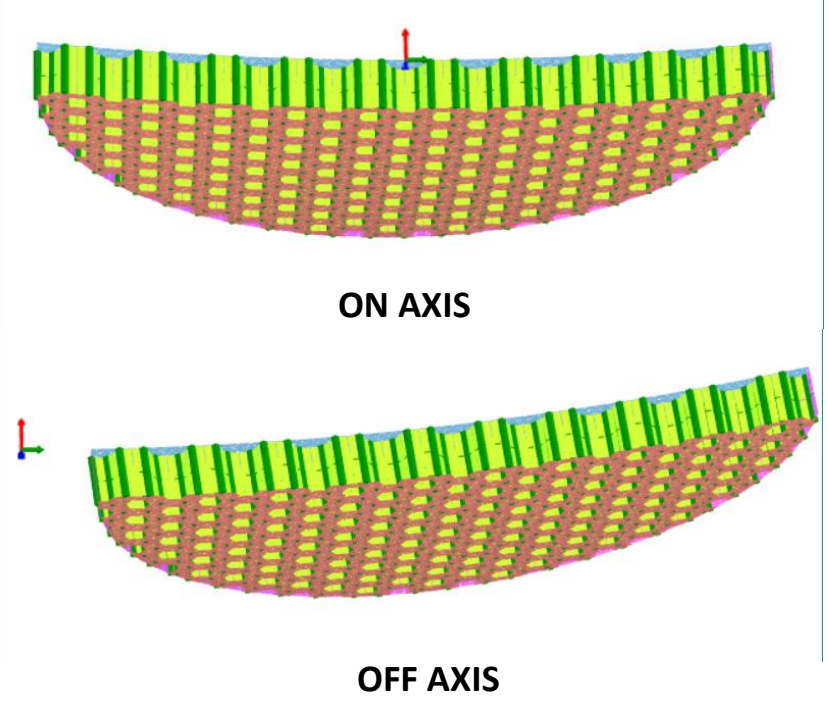

EXTREME UNDERCUT MILLED

One of the shortcoming of light-weighted Zerodur mirrors is the structural inefficient of any open back design when compared to a closed back (i.e. typical ULE design). The trade off is shown in the three levels of pocket milling used to overcome this issue. There is a clear cost and risk associated with each level of undercut. The thinner the wall, the higher the risk of inprocess damage (up to total loss of a blank after investing nearly complete cost) 


\section{ON AXIS VERSUS OFF AXIS}
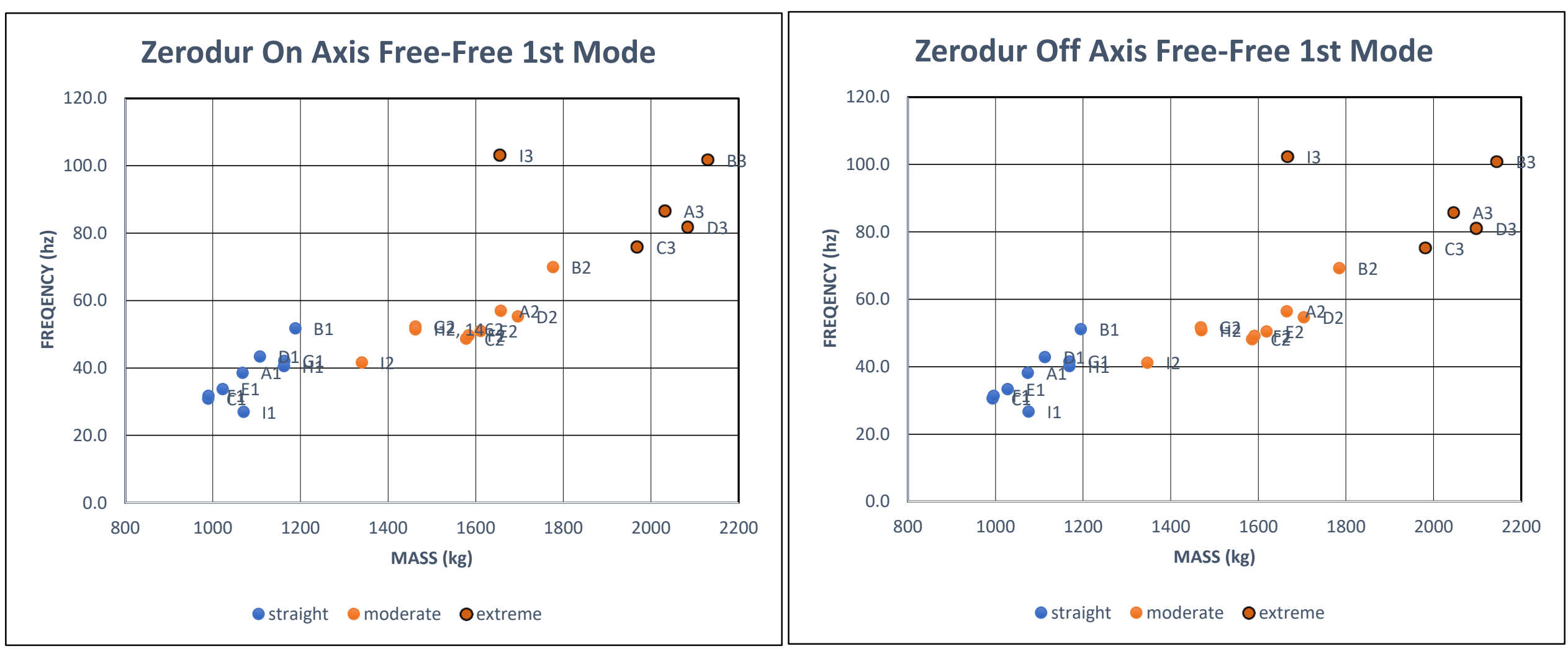

If based upon free-free modes only, there is little difference between on axis and off axis mass versus frequency. However, this is not the only criteria necessary for a system to work. 


\section{TYPICAL HARMONIC RESPONSE}

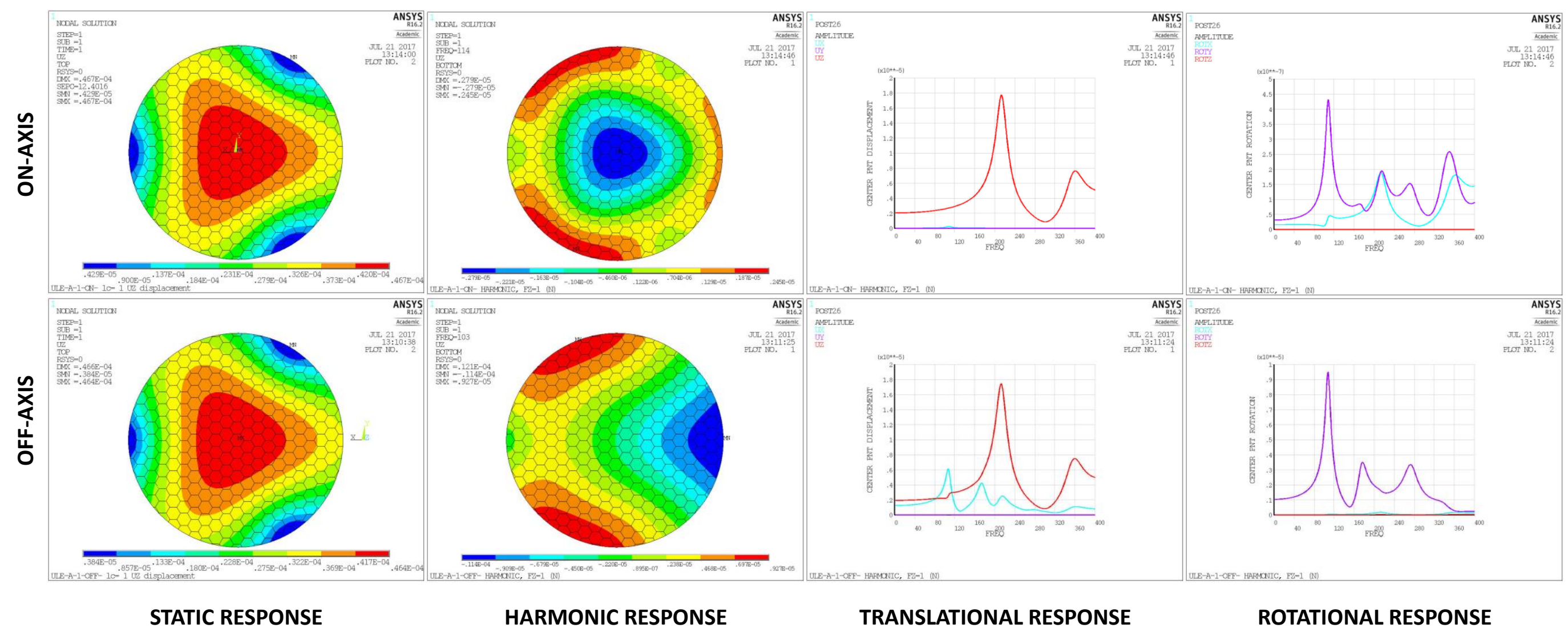

The possible ways to show the differences in on-axis and off-axis response are contour plots of displacements and rigid body displacement versus frequency response plots. 


\section{(a) COMPARISON OF ZERNIKE COEFFICIENTS}

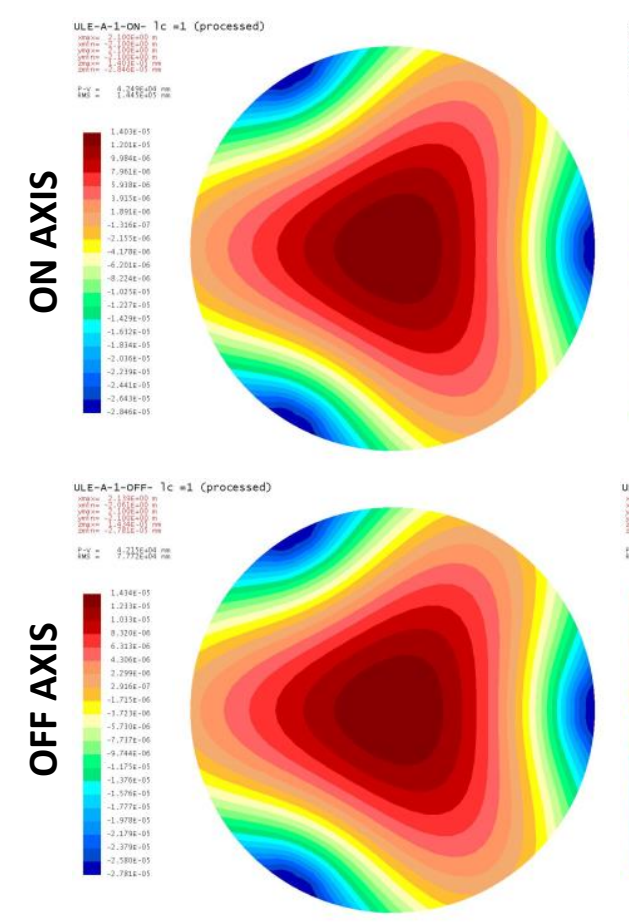

STATIC RESPONSE

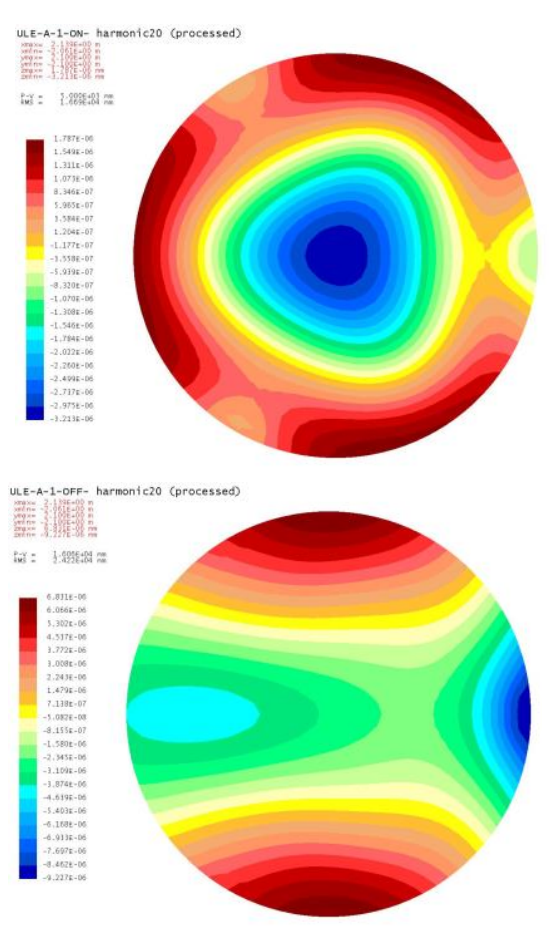

HARMONIC RESPONSE

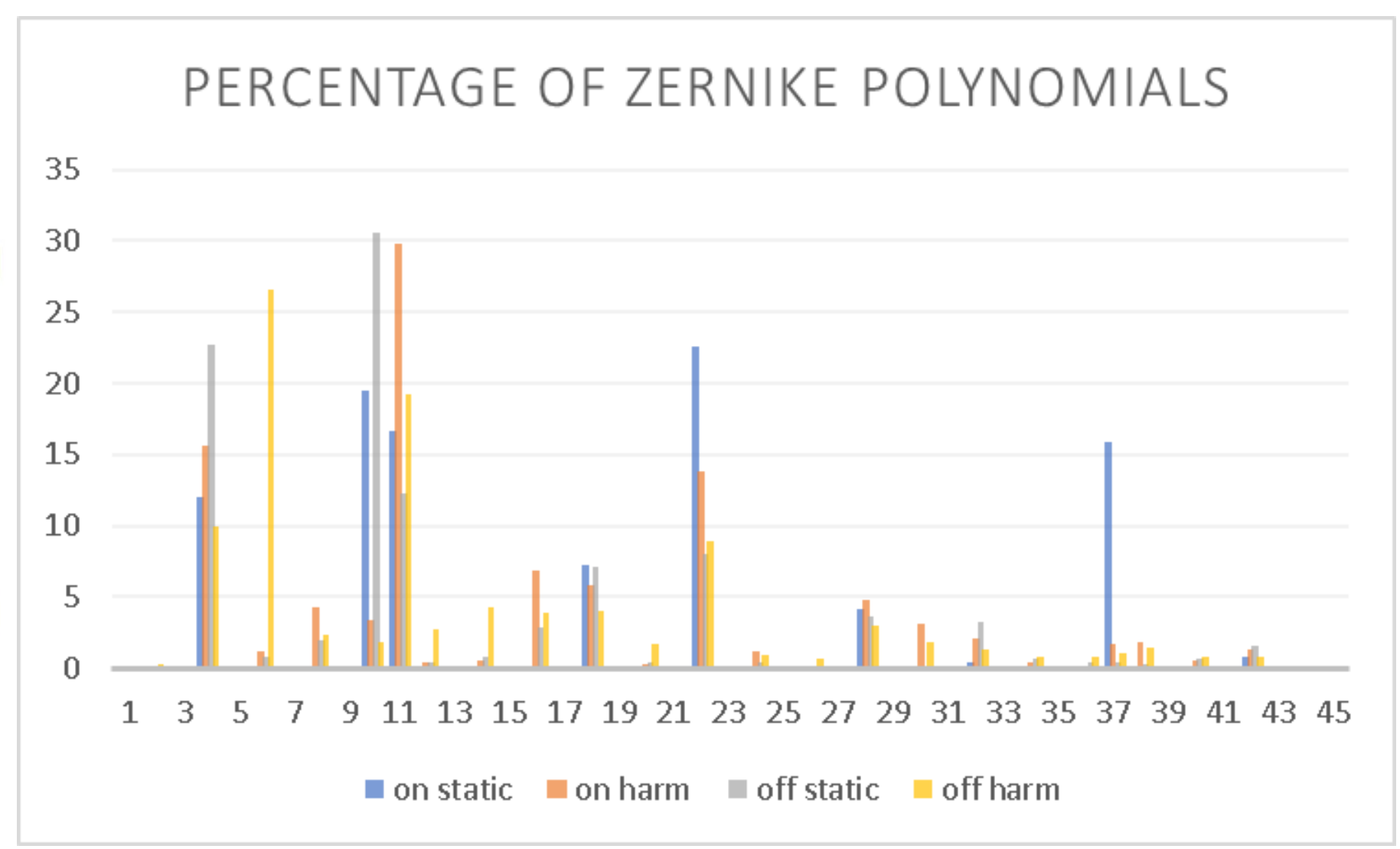

Another possible way to demonstrate the differences between on-axis and off-axis response is to show the proportional response broken down into Zernike coefficient percentages. While the amplitudes vary with input levels, the general shape of the response does not. The figure(s) above are all from the same geometric design point. 


\section{ULE RESULTS}

- Due to the large volume of results we are just going to rapidly flash thru the next twelve slides

- There are four cases per chart (columns)

- Small cell with 3 points on outer diameter

- Small cell with 6 points on outer diameter

- Large cell with 3 points on outer diameter

- Large cell with 6 points on outer diameter

- The response types per chart (rows)

- On-axis static response

- On-axis harmonic response

- Off-axis static response

- Off-axis harmonic response

- We will pause and discuss some of the implications for ULE, then get into the Zerodur Cases 


\section{ULE MENISCUS}

ULE MENISCUS PLATE-PLATE
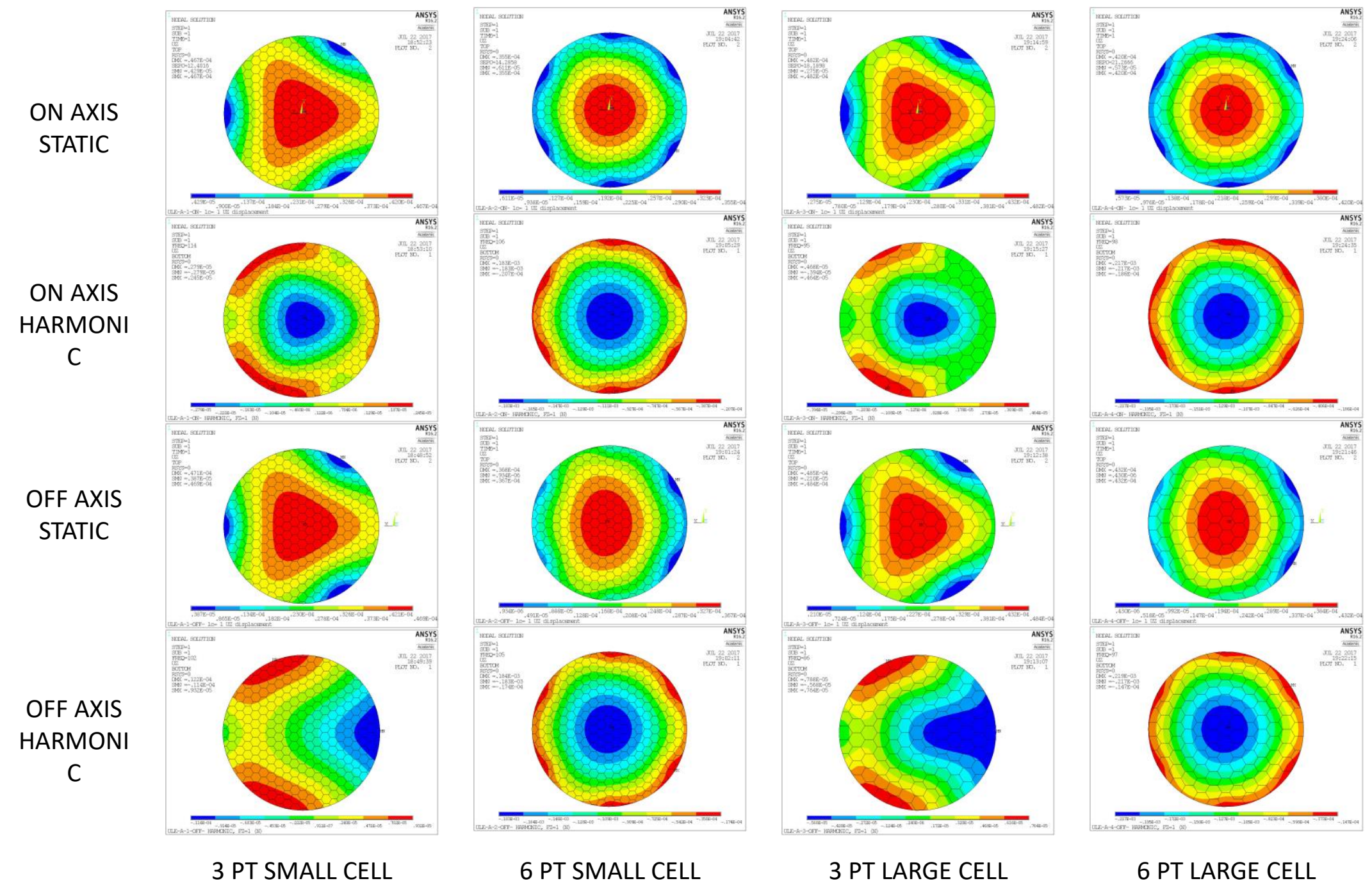


\section{ULE FLAT BACK}

ULE FLAT BACK PLATE-PLATE
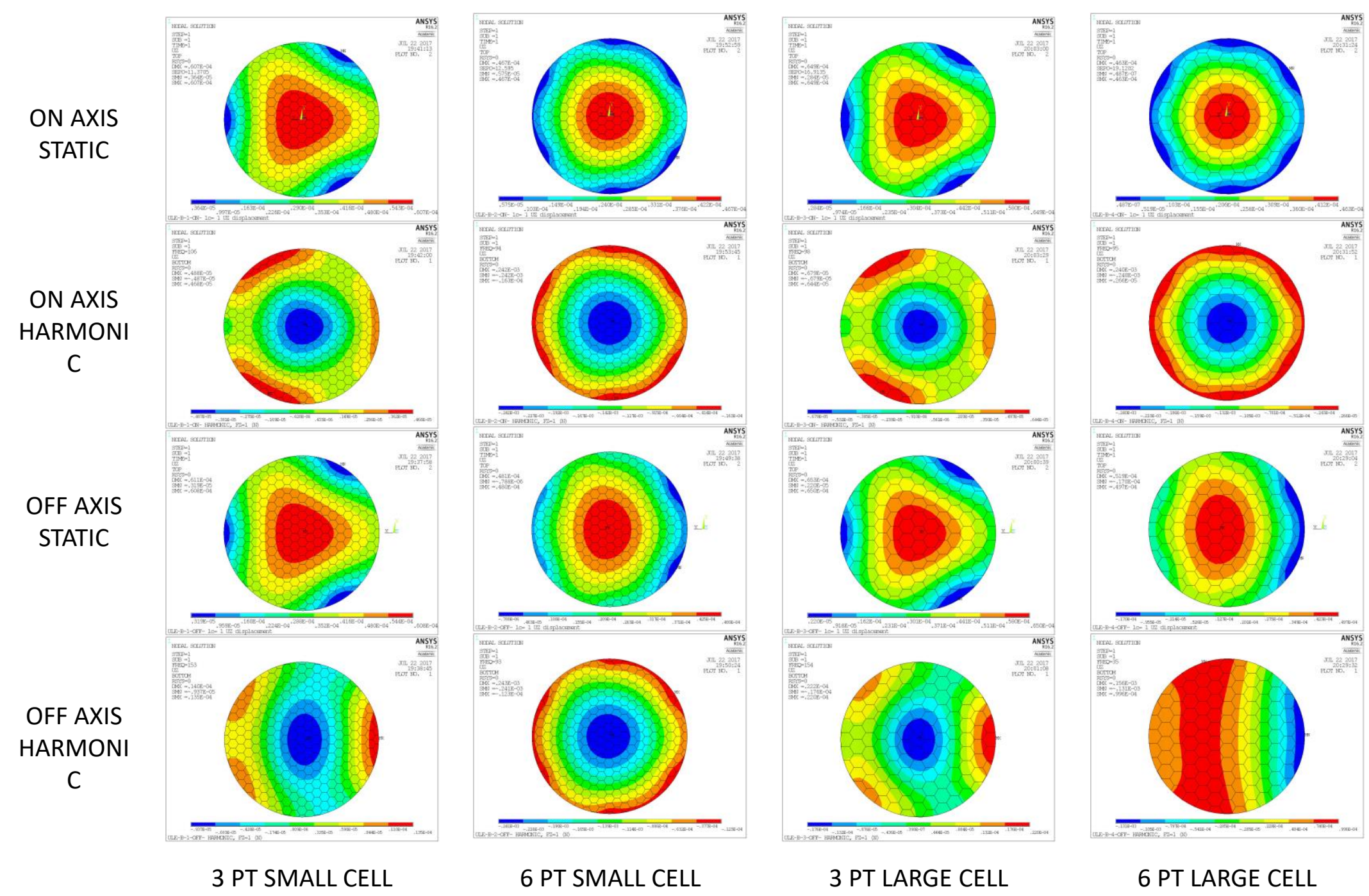


\section{ULE CONCAVE BACK}

ULE CONCAVE BACK PLATE-PLATE
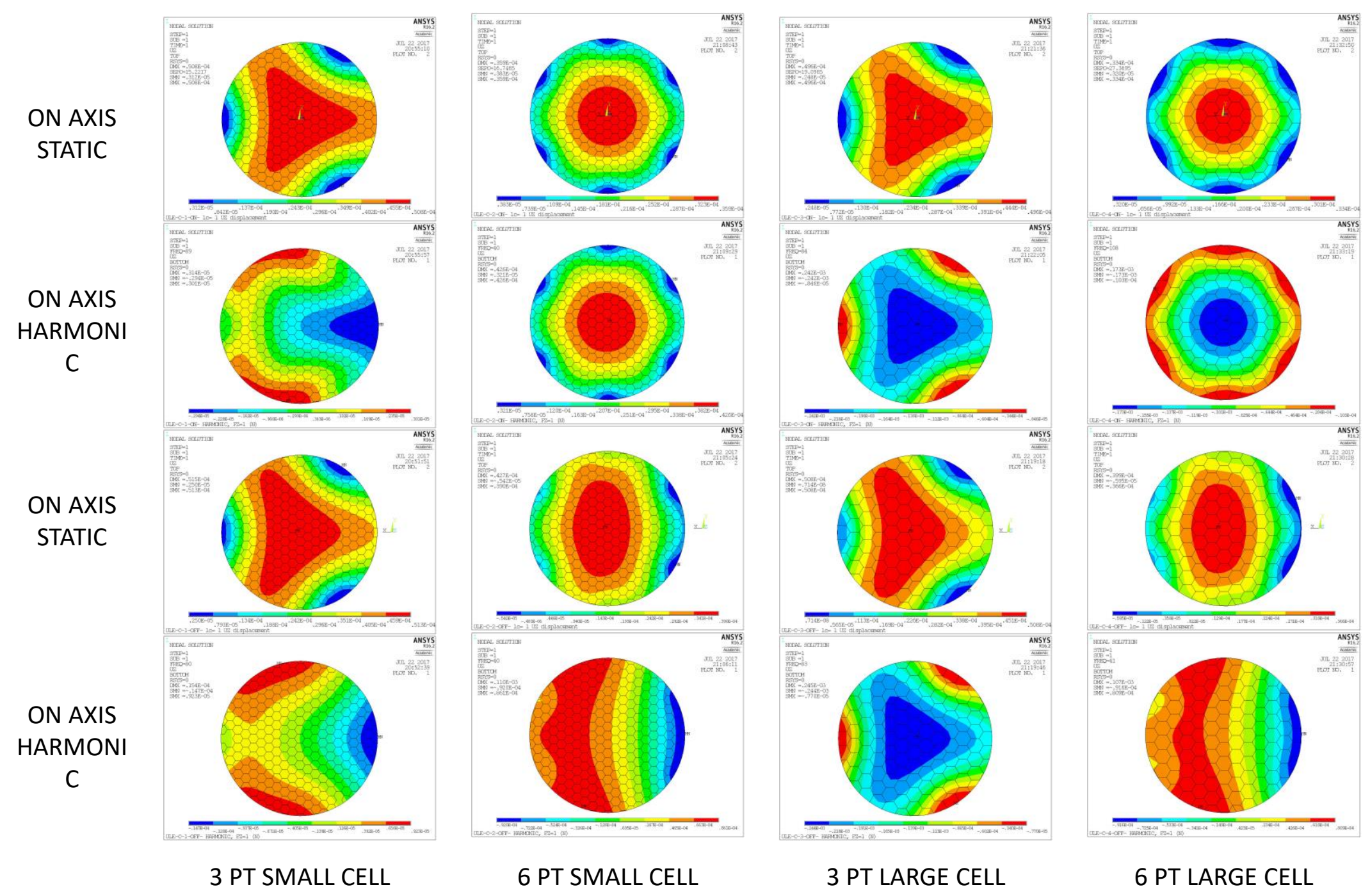


\section{ULE CONVEX BACK}

ULE CONVEX BACK PLATE-PLATE
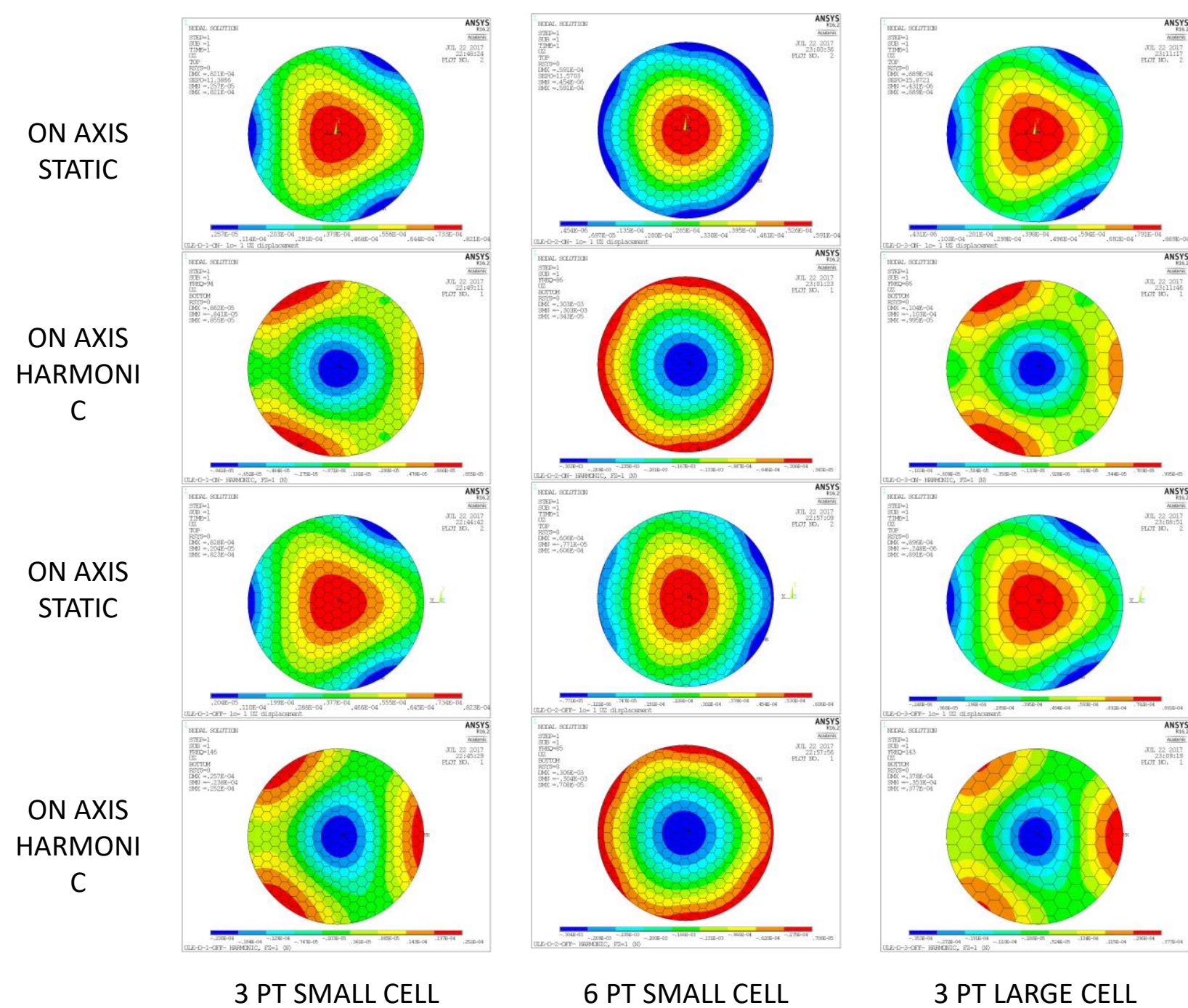

6 PT SMALL CELL

3 PT LARGE CELL

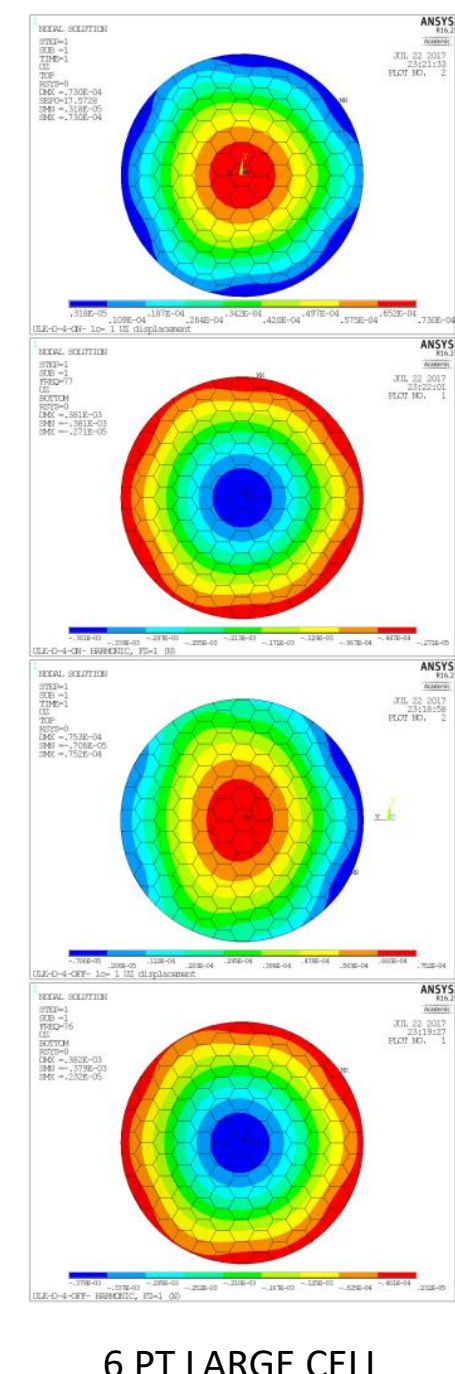

6 PT LARGE CELL 


\section{ULE MENISCUS}

ULE MENISCUS ISOGRID-PLATE
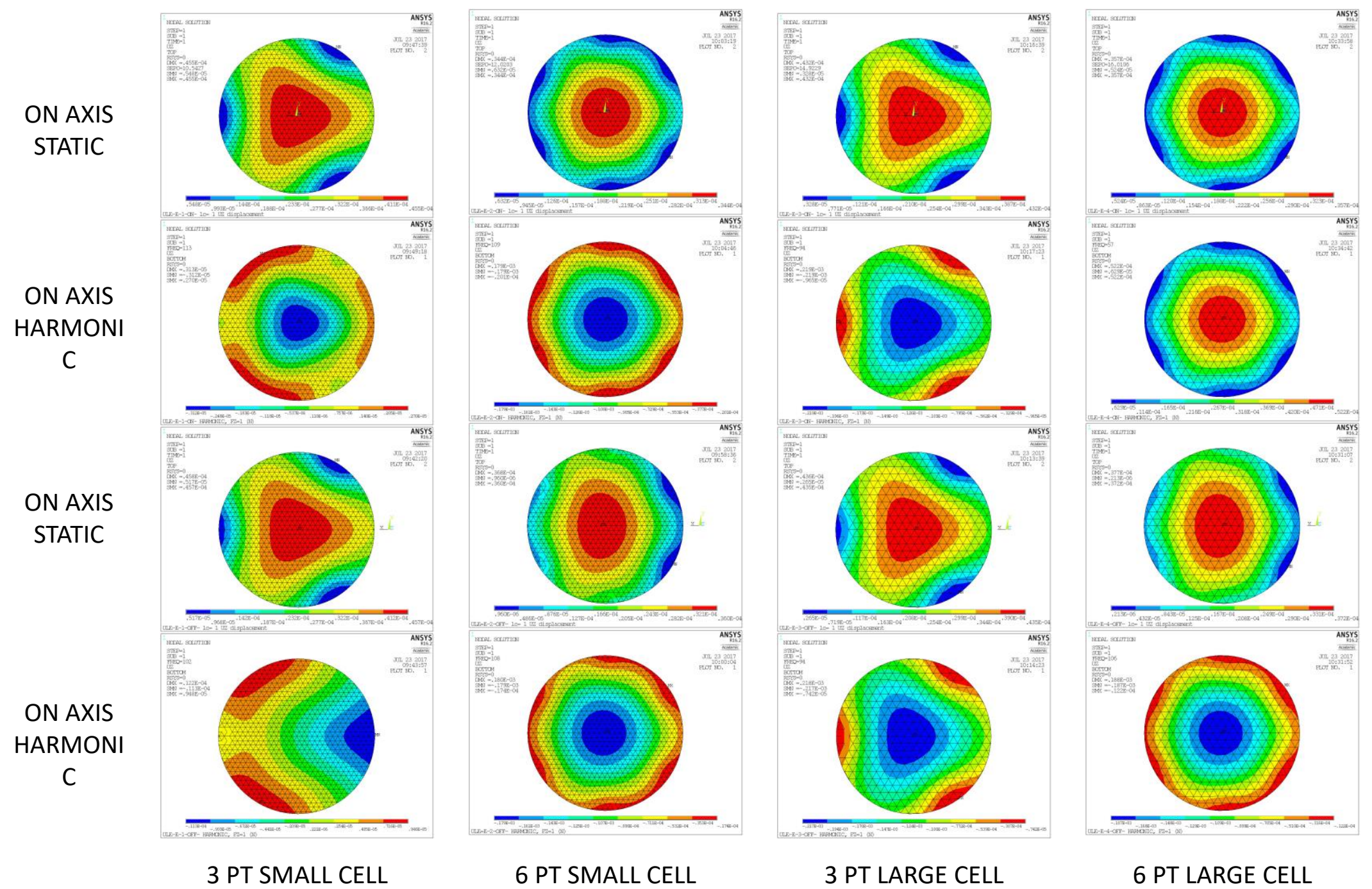


\section{ULE FLAT BACK}

ULE FLAT BACK ISOGRID-PLATE
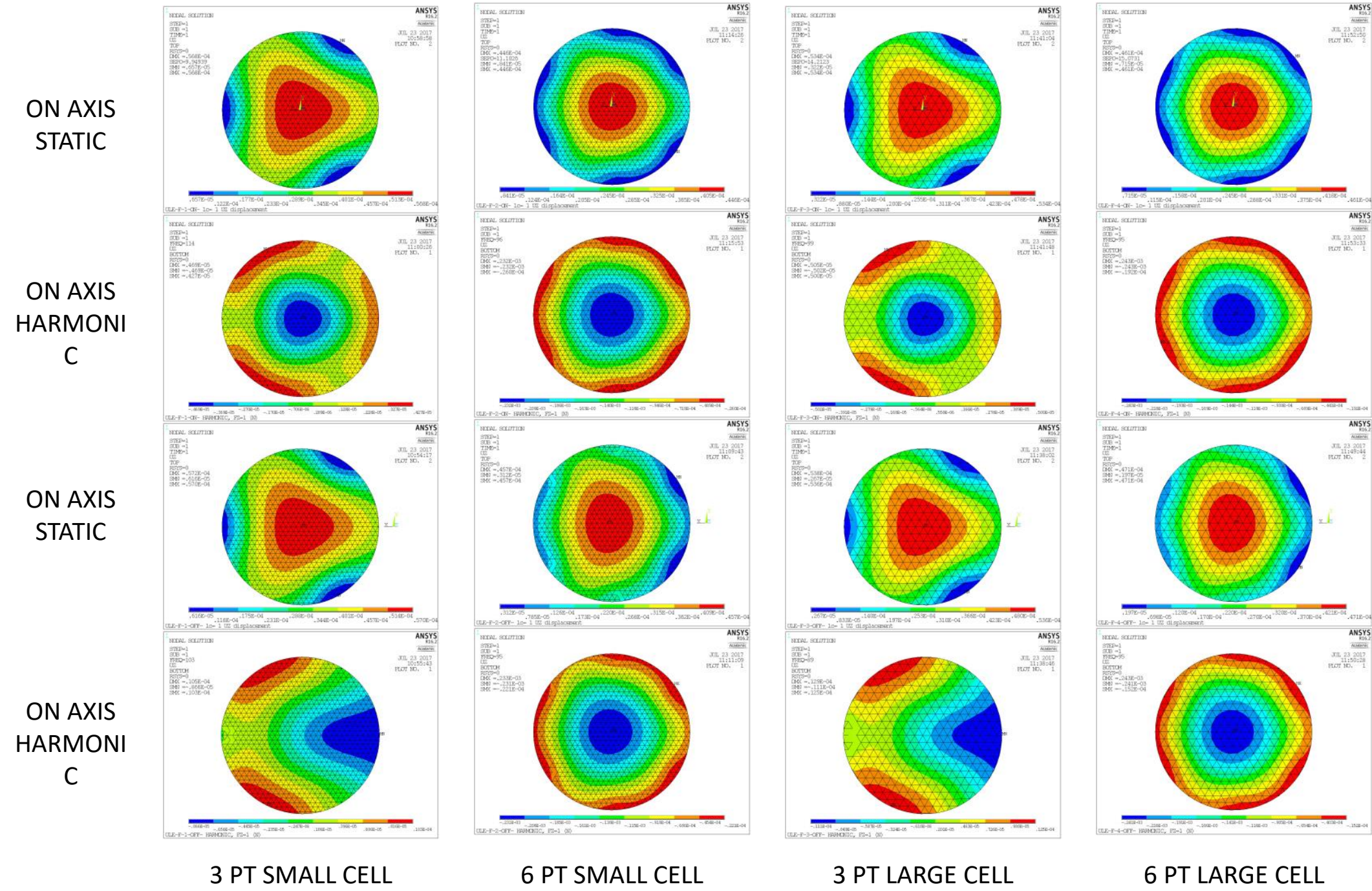

6 PT SMALL CELL

6 PT LARGE CELL 


\section{ULE CONCAVE BACK}

ULE CONCAVE BACK ISOGRID-PLATE
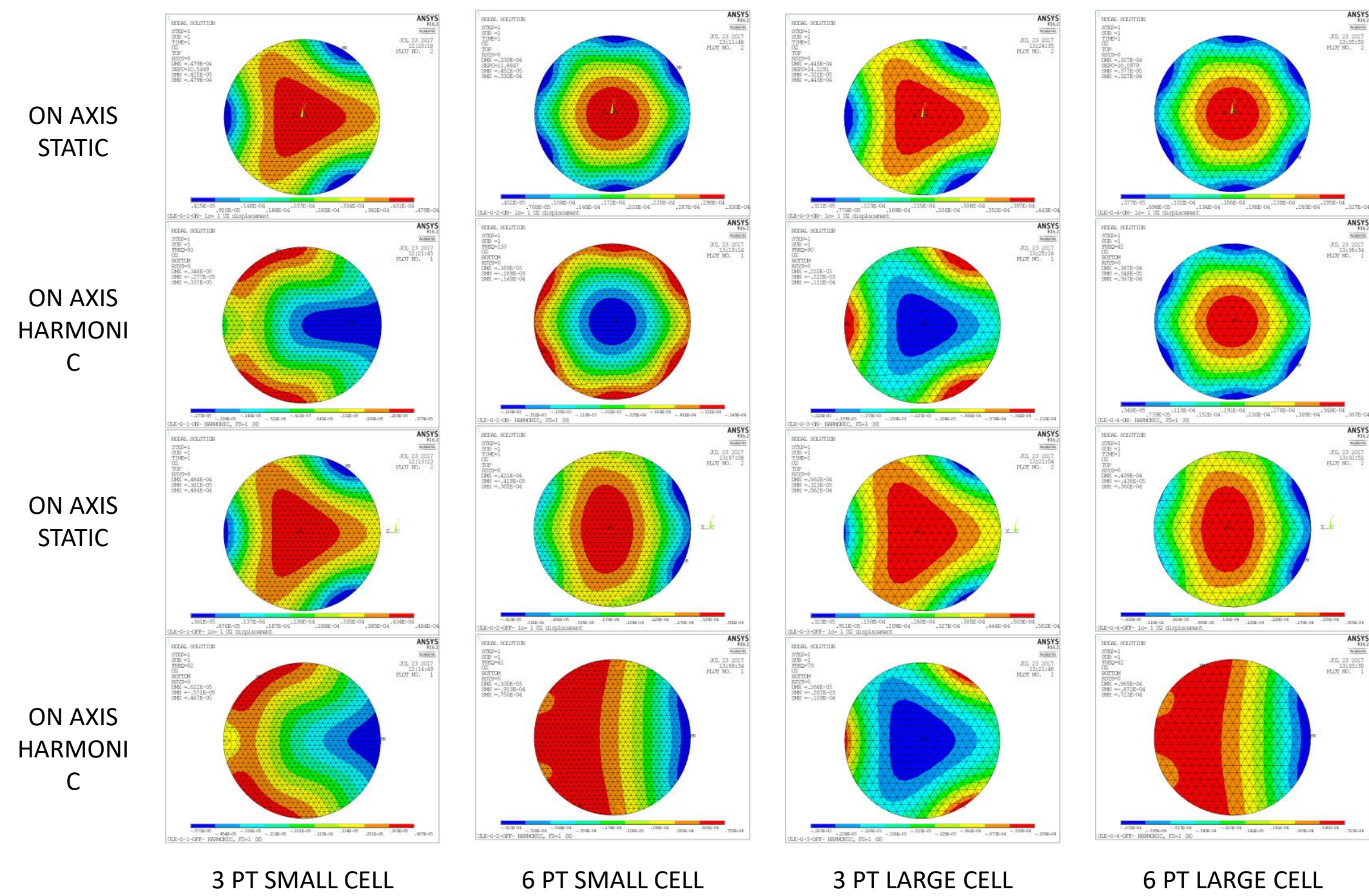


\section{ULE CONVEX BACK}

ULE CONVEX BACK ISOGRID-PLATE
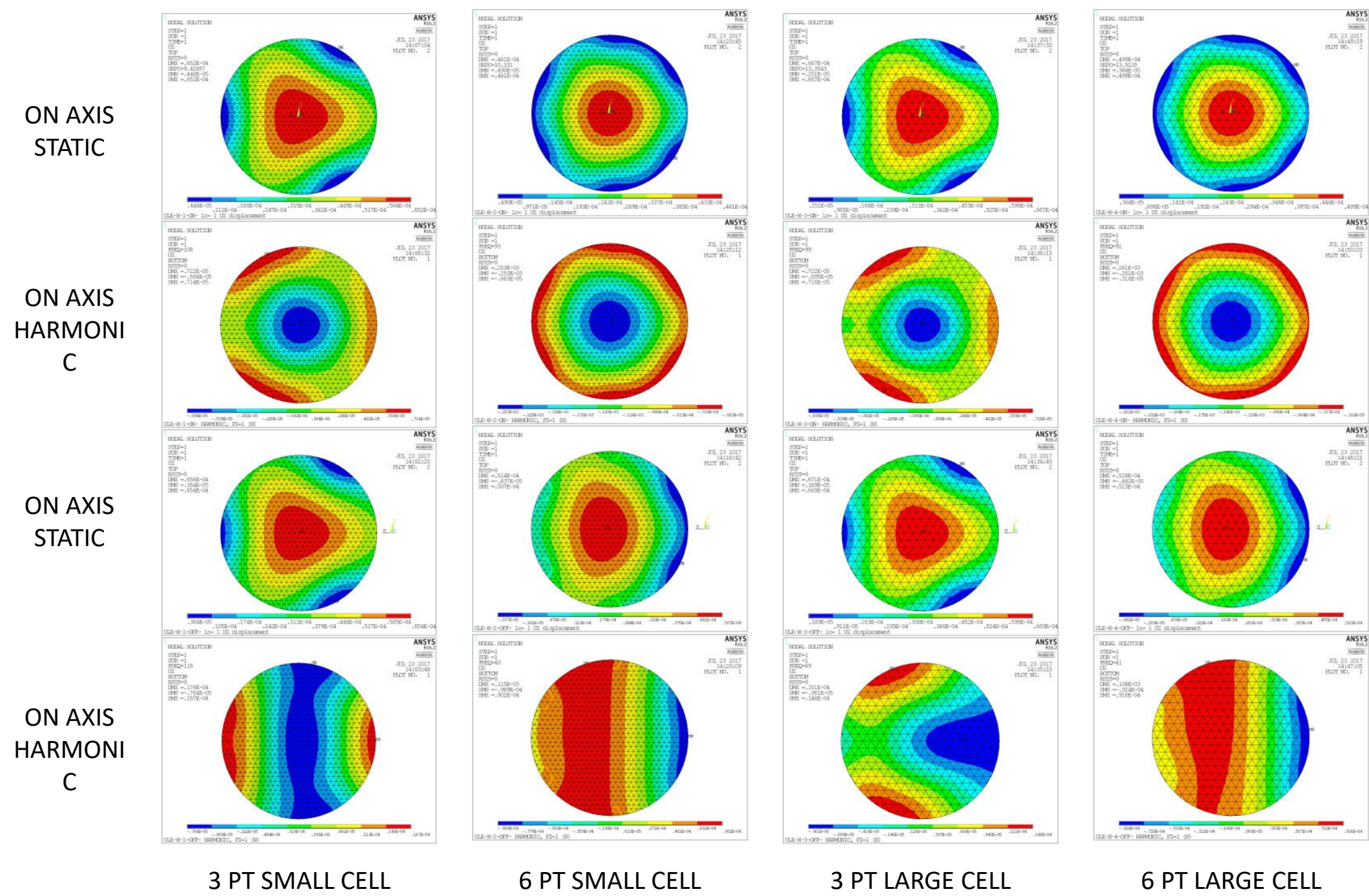


\section{ULE MENISCUS}

ULE MENISCUS ISOGRID-ISOGRID

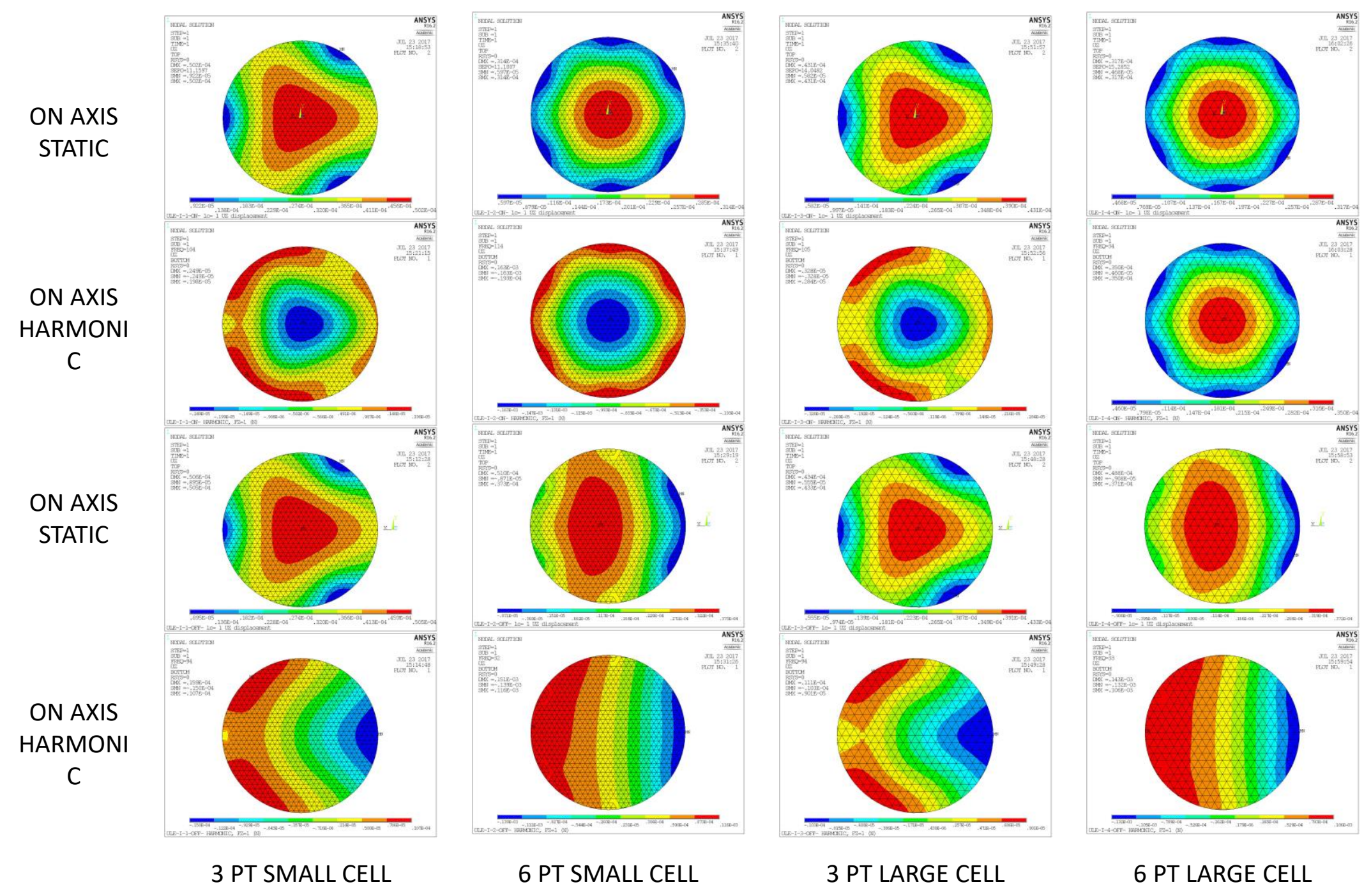




\section{ULE FLAT BACK}

\section{ULE FLAT BACK ISOGRID-ISOGRID}
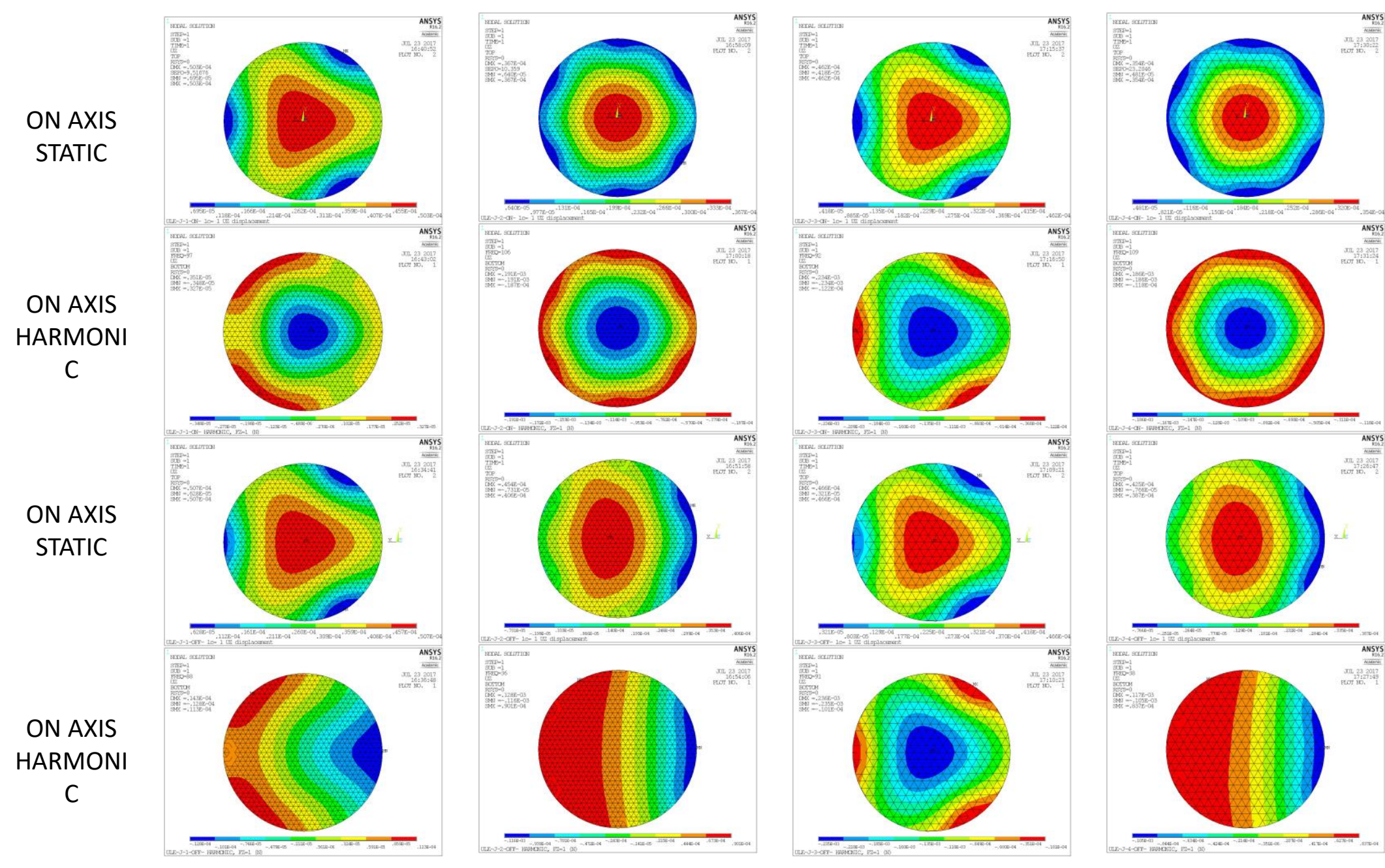

3 PT SMALL CELL

6 PT SMALL CELL

3 PT LARGE CELL

6 PT LARGE CELL 


\section{ULE CONCAVE BACK}

ULE CONCAVE BACK ISOGRID-ISOGRID

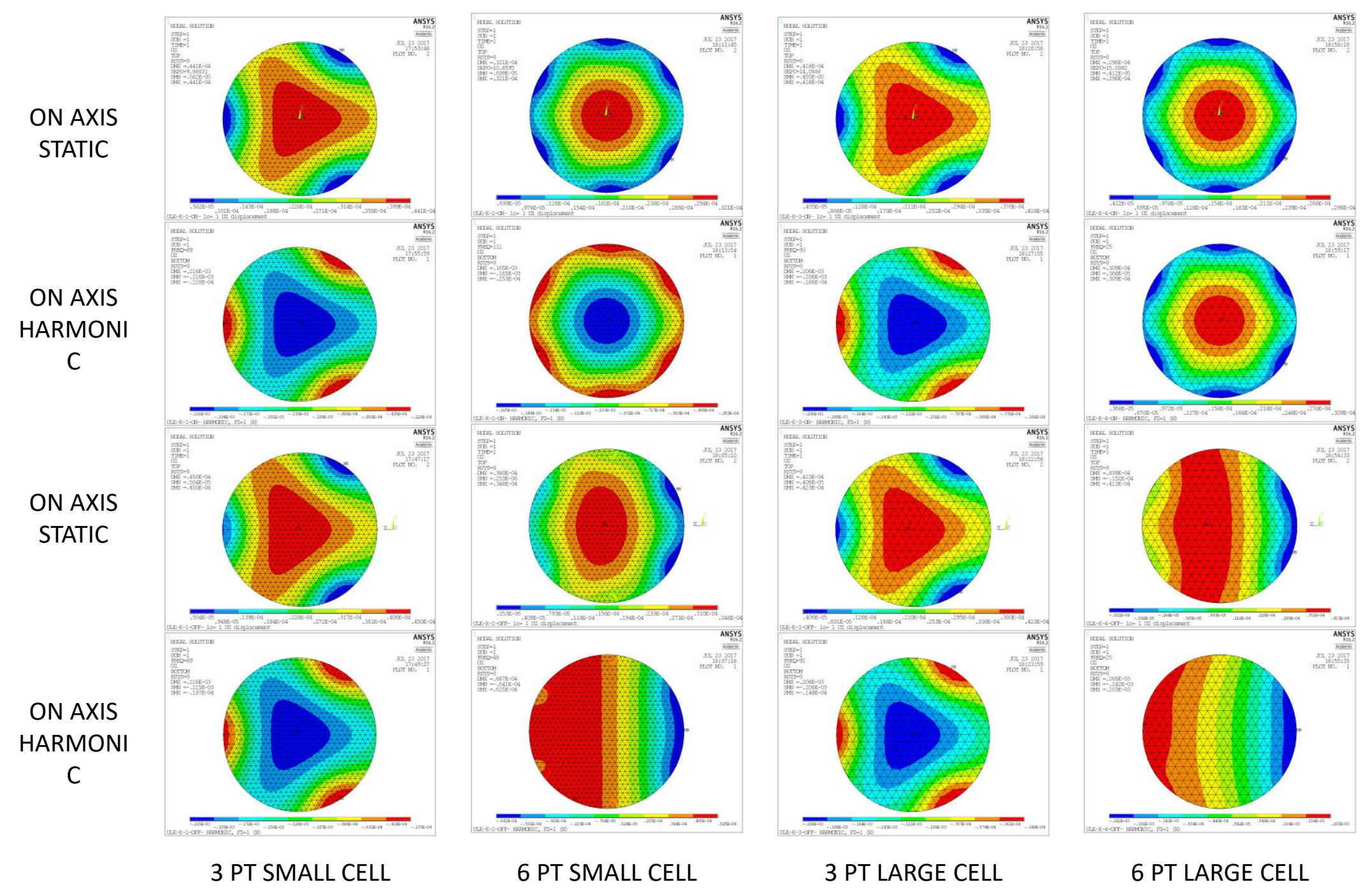




\section{ULE CONVEX BACK}

ULE CONVEX BACK ISOGRID-ISOGRID
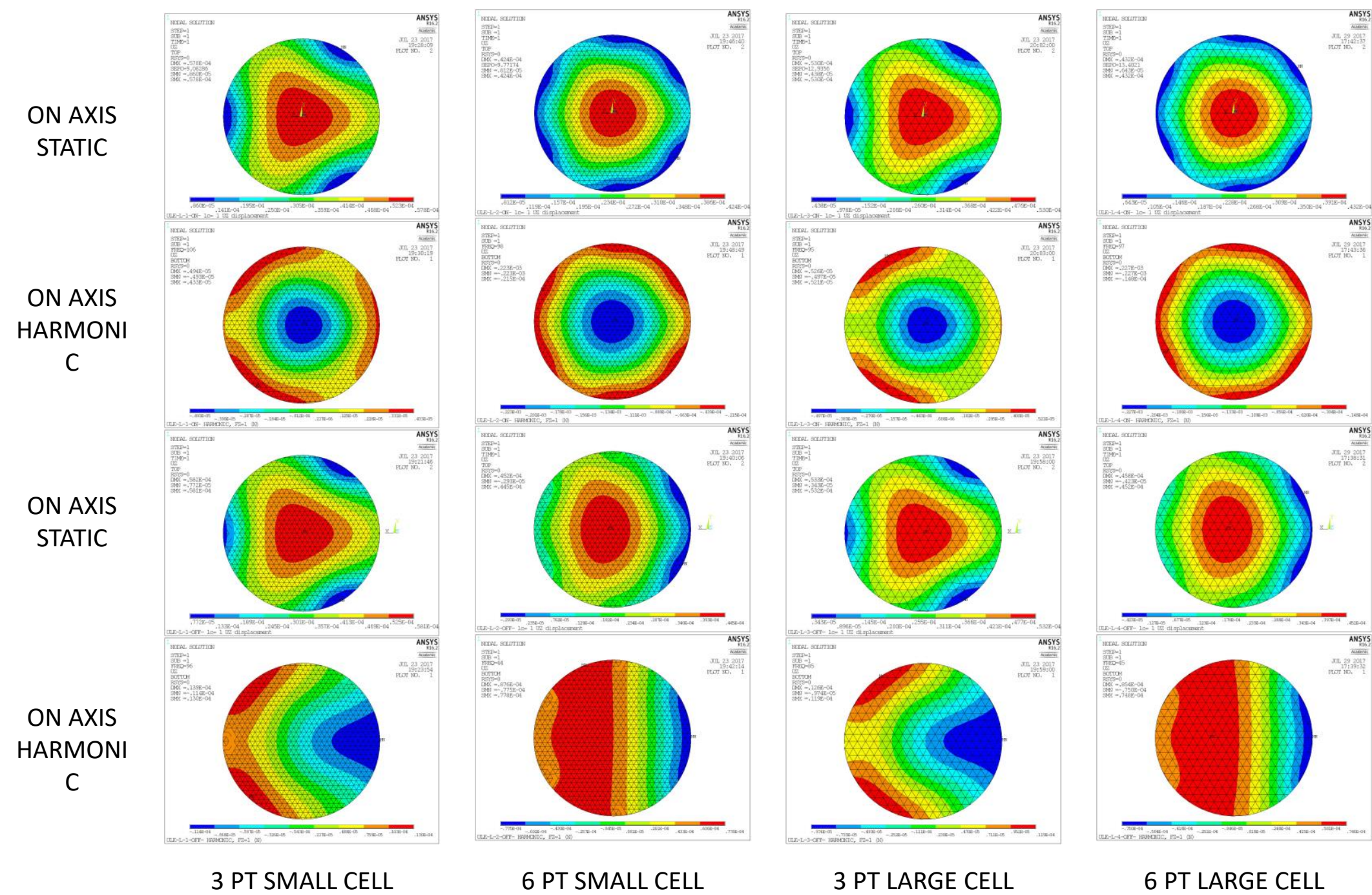


\section{(a) A LITTLE DISCUSSION ON THE ULE RESULTS}

- Its pretty clear that the static shape is not always a good indicator of how the mirror will respond to harmonic excitation.

- It seems to be the strongest relationships to differences are in mass distribution and support system geometry.

- For off-axis cases, there is always cross talk between axial and lateral modes, with maximum response NOT always associated with lowest mode, but rather highest modal participation factor in the axial direction.

- The wide frequency spread for models with essentially the same parameters seems to be related to local attachment detail rather than global bending behavior. 


\section{ZERODUR RESULTS}

- The Zerodur study was done after the ULE study, and included variations radial position of the supports ( $3 \& 6$ point for the first case and just the 3 point for the rest

- There are on-axis and off-axis cases per chart (columns)

- On-axis with 3 points on $100 \%$ outer diameter

- On-axis with 3 points on $75 \%$ outer diameter

- On-axis with 3 points on $65 \%$ outer diameter

- Off-axis with 3 points on $100 \%$ outer diameter

- Off-axis with 3 points on $75 \%$ outer diameter

- Off-axis with 3 points on $65 \%$ outer diameter

- The response chart (rows)

- Static response (displacement map)

- Peak harmonic response (mirror center translations)

- Peak harmonic response (mirror center rotations)

- Peak harmonic response (displacement map) 


\section{SUPPORT CONFIGURATIONS STUDIED}
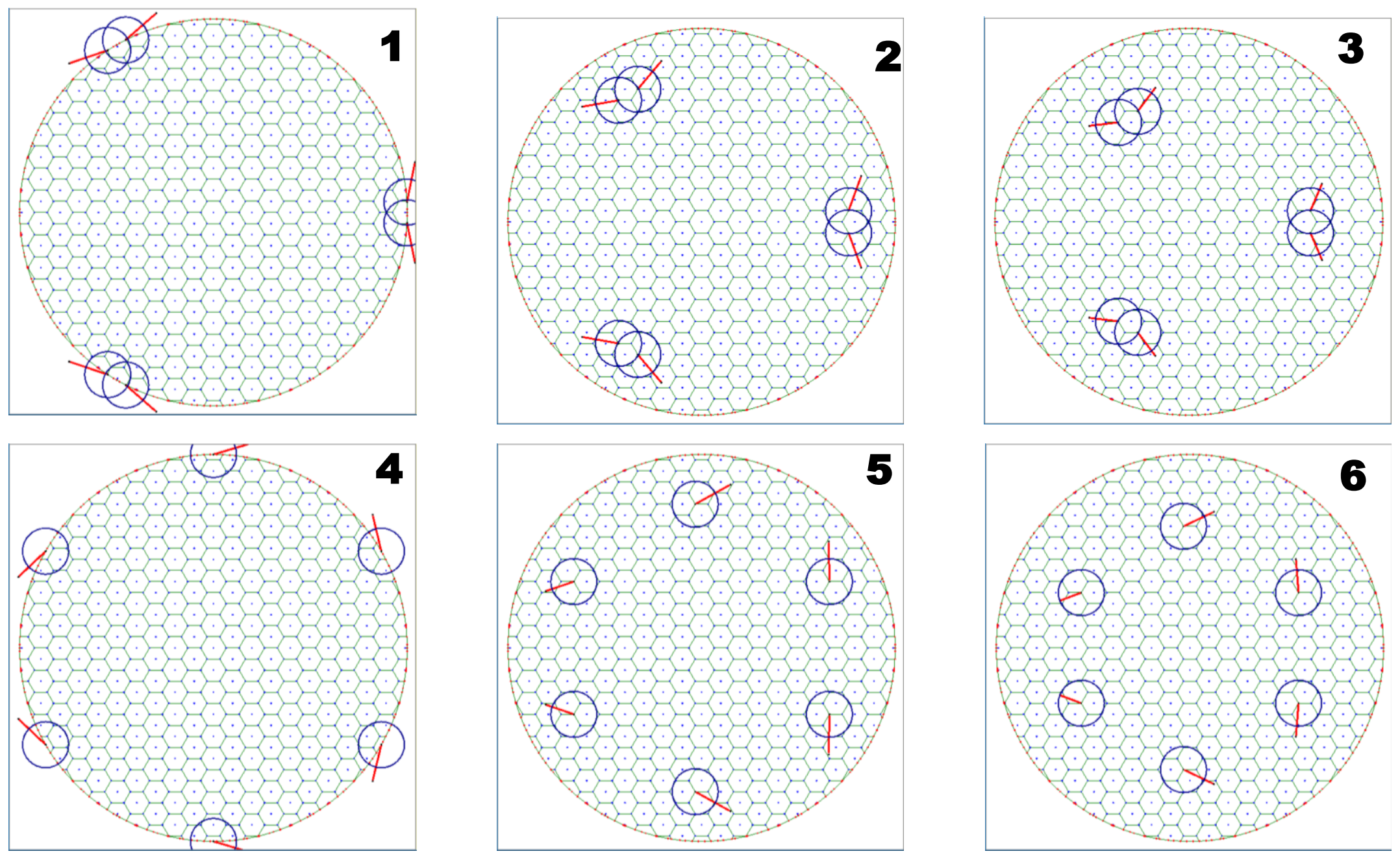
$-10=$ 


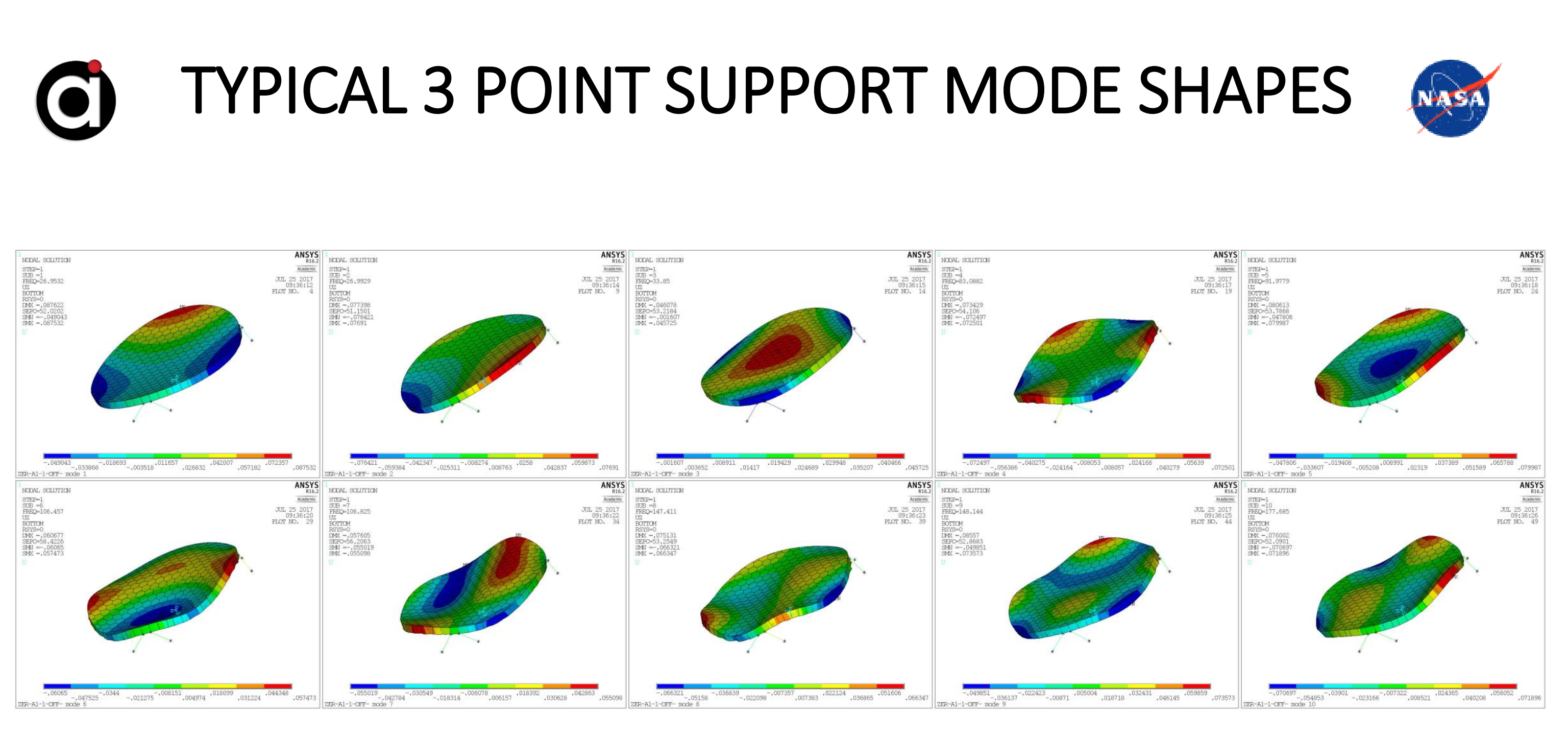




$$
00
$$




\section{(a) ZERODUR MENISCUS CASE (ON-AXIS)}

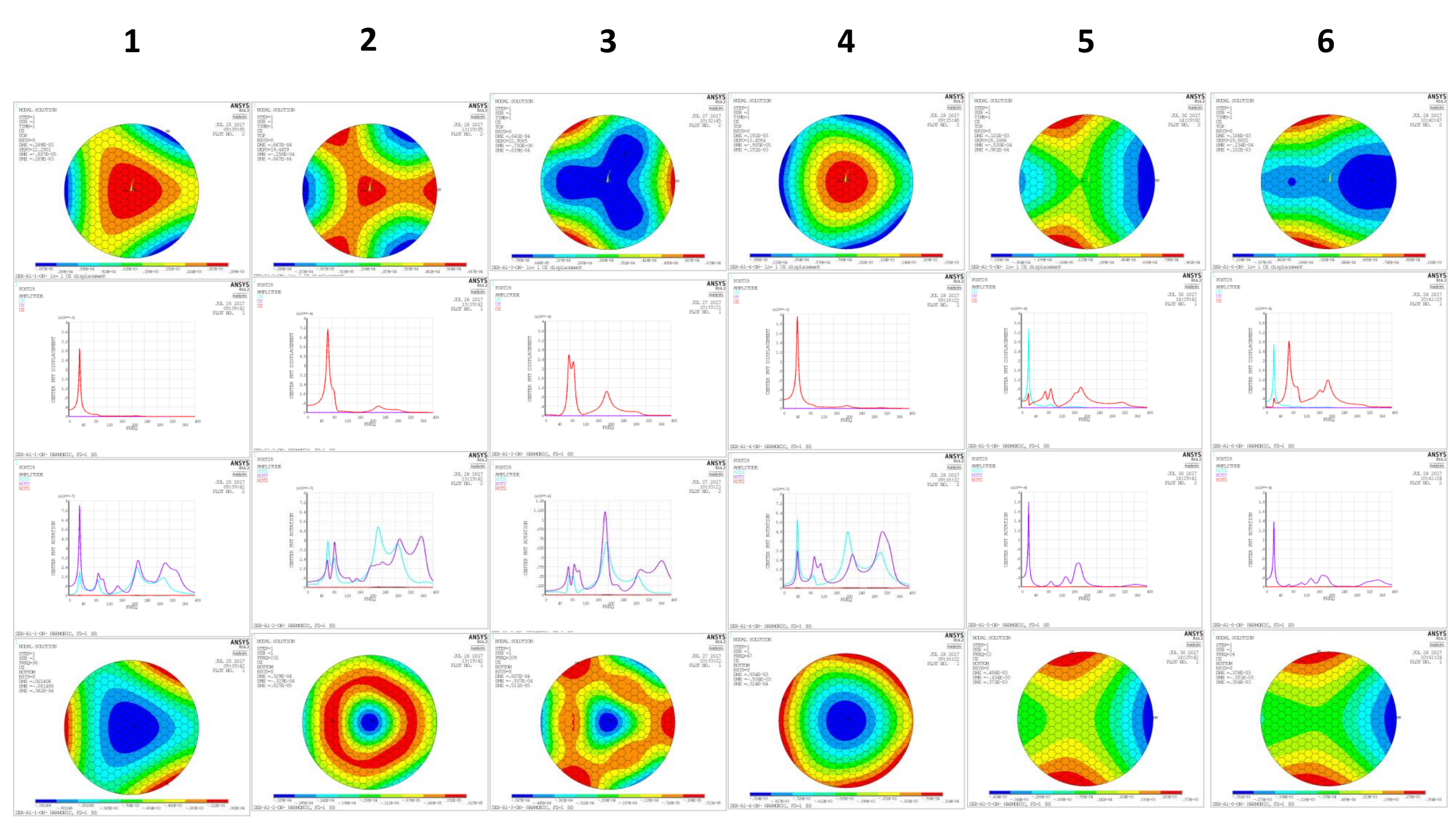




\section{(a) ZERODUR MENISCUS CASE (OFF-AXIS)}

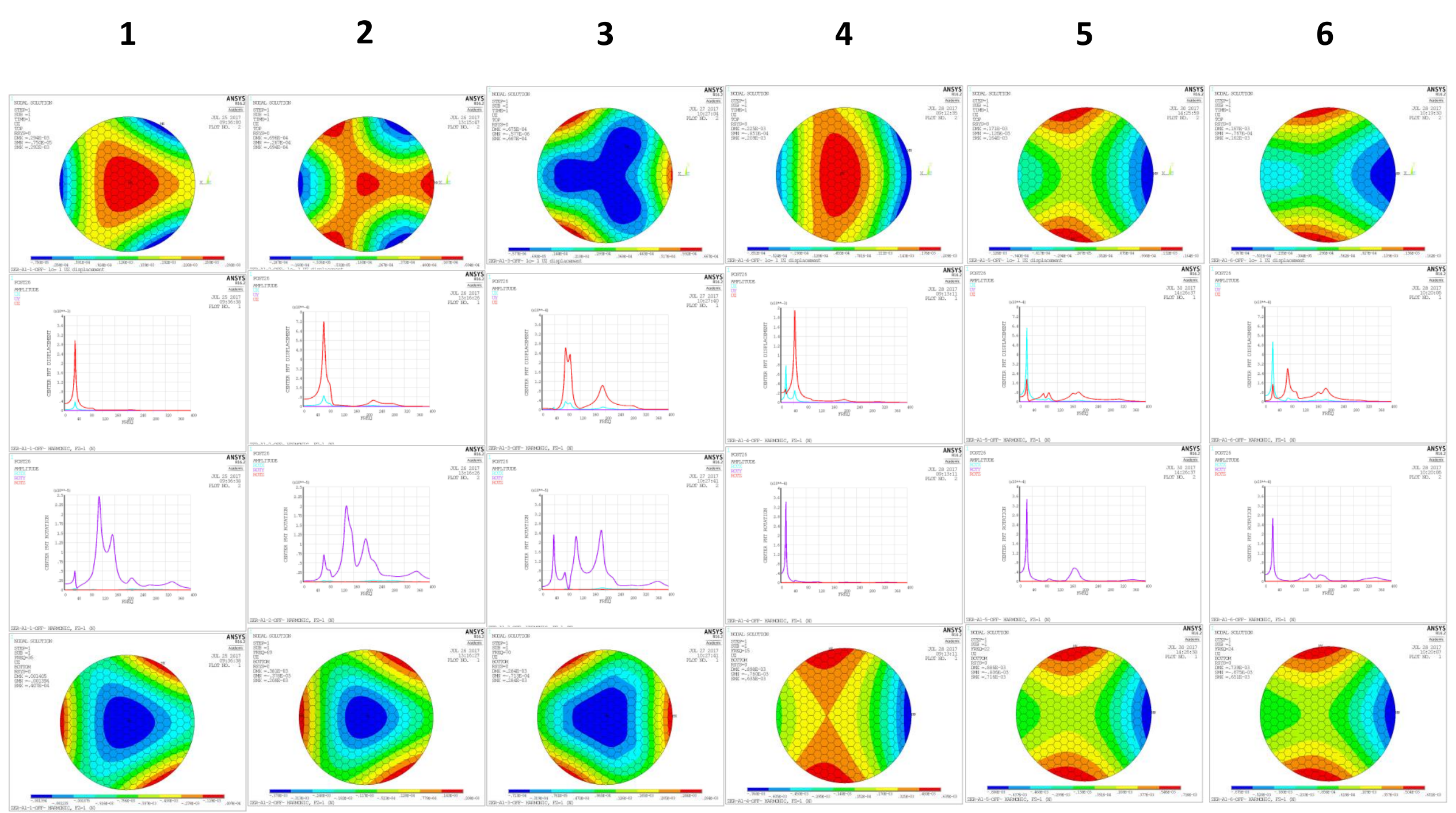




\section{(a) ZERODUR FLAT BACK SUPPORT STUDY}
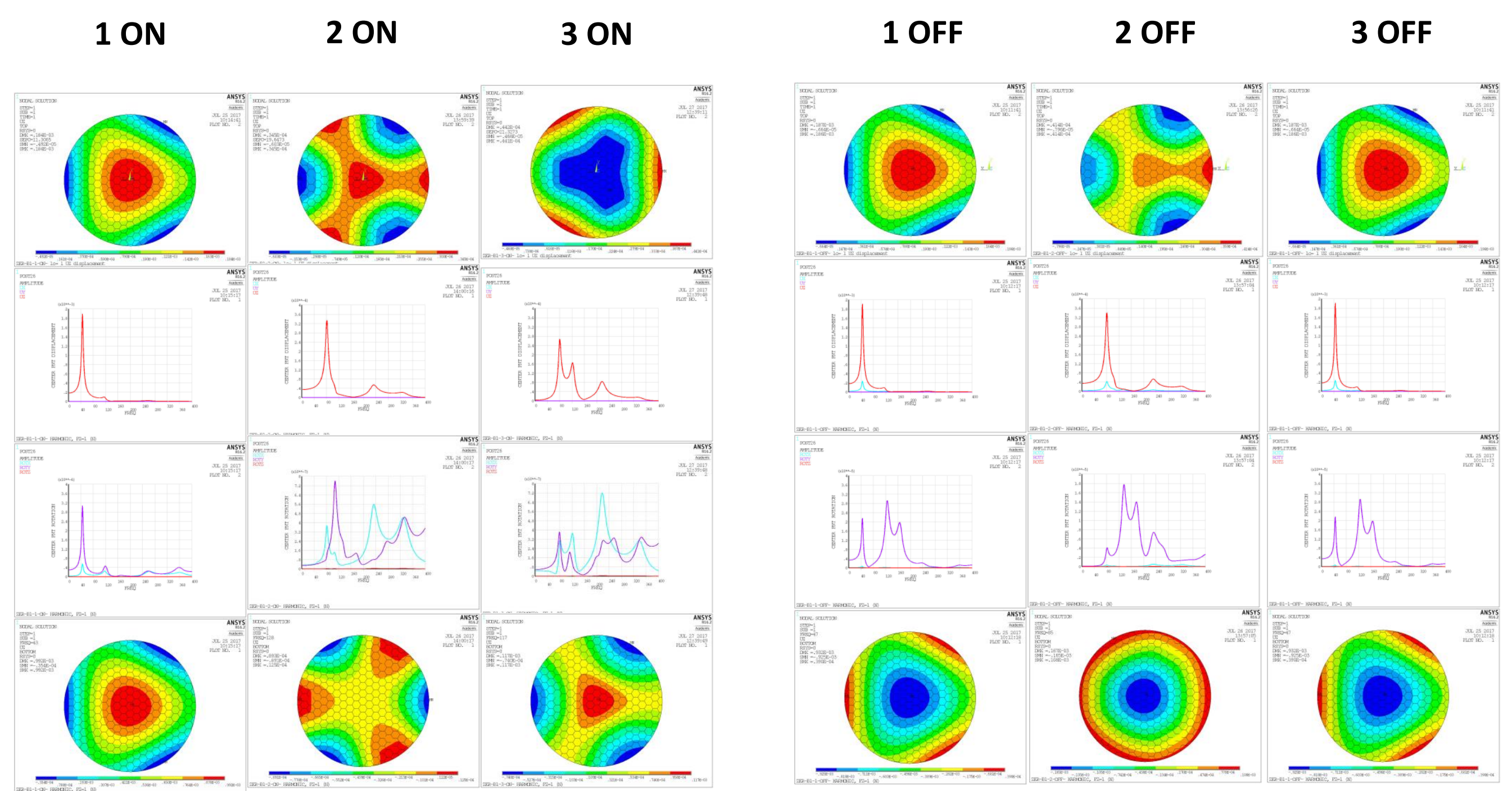


\section{(a) ZERODUR FLAT BACK POCKETING STUDY}

ON-AXIS

STRAIGHT MODERATE EXTREME

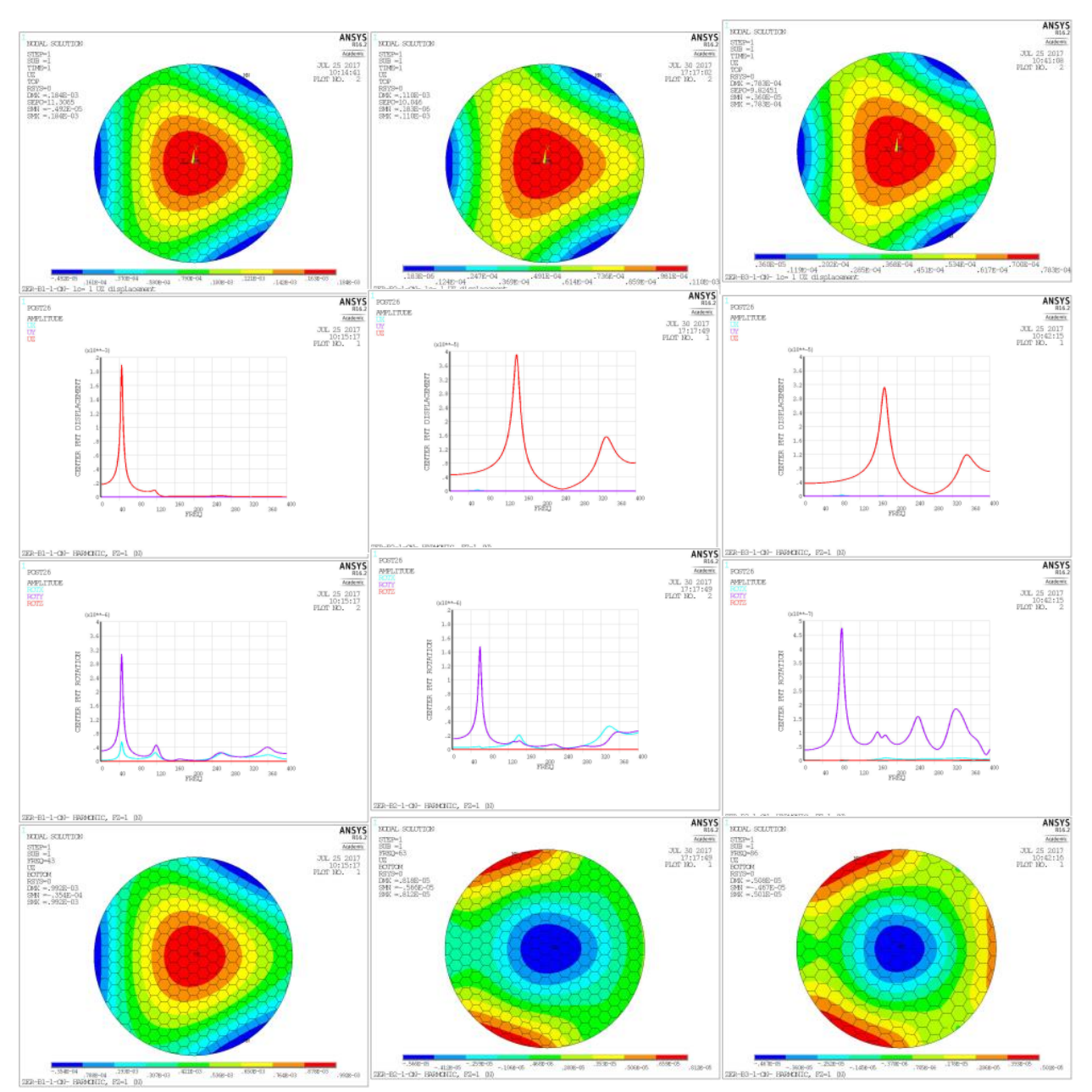

OFF-AXIS

STRAIGHT MODERATE EXTREME

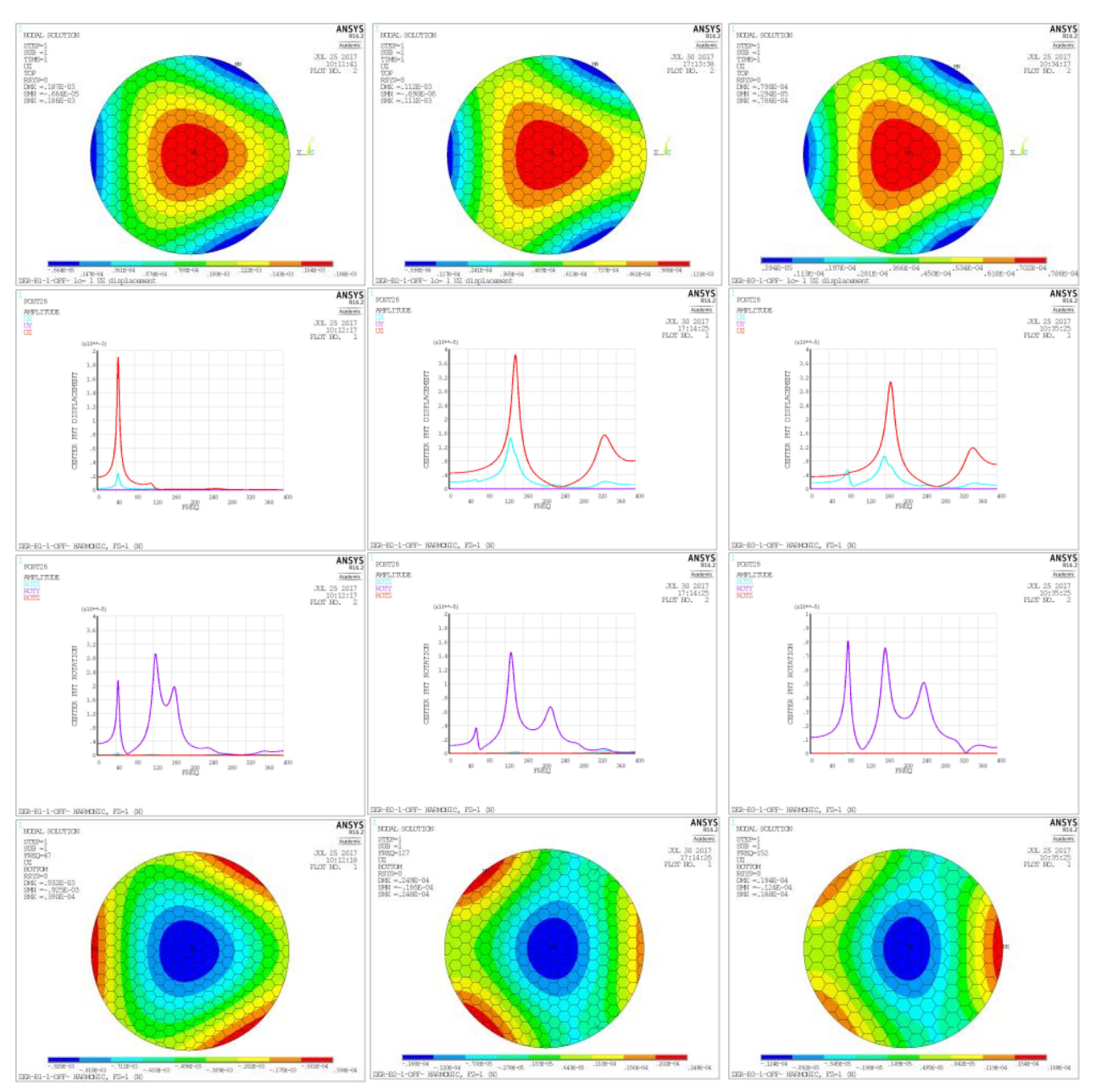




\section{SUMMARY}

- We have looked at the two leading options for the primary mirror, ULE and Zerodur. The study considered mirror shape and mounting considerations.

- There is too much data to present in a presentation, so we showed some representative results which answered most of the questions we posed at the beginning.

- The results show what can be accomplished with well proven methods and realistic dimensions.

- The baseline for HABEX was selected as a moderate under cut meniscus Zerodur mirror with 3 point outer perimeter support. The rationale has to do with coronagraph insensitivity to certain distortions (Zernikes), cost and risk. 
- Finish processing all the raw data and publishing a full report

- Do a trade study on the optimal suspension geometry and local reinforcement scheme for the baseline mirror design.

- Integrate the mirror and suspension into the telescope level model. 